\title{
Location Planning of Urban Distribution Center under Uncertainty: A Case Study of Yogyakarta Special Region Province, Indonesia
}

\author{
Bertha Maya Sopha (D), Anna Maria Sri Asih iD, Putri Dewi Nursitasari iD \\ Industrial Engineering Program, Department of Mechanical and Industrial Engineering, Universitas Gadjah Mada (Indonesia) \\ bertha_sopha@ugm.ac.id, amsriasih@ugm.ac.id,putridewinursitasari@gmail.com
}

Received: January 2018

Accepted: June 2018

\begin{abstract}
:
Purpose: The paper aims at proposing a framework of hybrid spatial-fuzzy multi-criteria decision-making and demonstrating application of the framework to evaluate and select the appropriate location for Urban Distribution Center in Yogyakarta Special Region Province, Indonesia. The study has been inspired by the need to evaluate the Urban Distribution Center initiative, i.e., Jogja Inland Port by local government that has been hampered due to lack of participating companies.

Design/methodology/approach: The proposed framework consists of two steps of analysis. First, spatial analysis to generate alternative locations using weighted Geographical Information System data; second, fuzzy multi-criteria decision-making to select the best location. Fuzzy Technique for Order of Preference by Similarity to Ideal Solution was applied to deal with multi-criteria, multiple stakeholders, and uncertainty. Accessibility, security, connectivity of multi-modal transport, costs, environmental impact, proximity to customers, proximity to suppliers, resource availability, expansion possibility, service quality, are taken as the decision criteria. Local government of Yogyakarta province, practitioners, and logistic expert, are involved as representative participants in evaluating the Urban Distribution Center location of Yogyakarta Special Region Province.
\end{abstract}

Findings: The proposed framework has indicated that the Jogja Inland Port is not the best alternative. A joint warehouse managed by a group of private companies located in Berbah (Sleman district) appears to be the best alternative location for Urban Distribution Center. Consistent results are also found by using other approaches (Intuitionistic Fuzzy Technique for Order Preference by Similarity to Ideal Solution and Set Pair Analysis).

Research limitations/implications: In addition to the government, expert, and practitioners that involved in this study, future research could engage local residents as decision makers to refine the results, as various stakeholders may come up with different preferences.

Practical implications: From a practical point of view, the application of combined approach (integrating spatial analysis using weighted Geographical Information System data and fuzzy multi-criteria decision making) is a promising approach in dealing with Urban Distribution Center location problem which is characterized by multi-criteria, multiple stakeholders, spatial-related issues, and uncertainty.

Social implications: The unsuccessful establishment of Jogja Inland Port implies that Urban Distribution Center location problem is a complex system, involving multifaceted factors that should be considered simultaneously. 
Originality/value: The research proposes a framework to evaluate and select the appropriate location for Urban Distribution Center through combined approach of weighted Geographical Information System data and fuzzy multi-criteria decision-making which involves relevant stakeholders.

Keywords: urban distribution center, location planning, hybrid spatial-fuzzy multi-criteria decision-making, Yogyakarta Special Region Province

\section{Introduction}

As cities become denser and demand for goods has dramatically increased, the need of transport activity has undoubtedly grown tremendously. The growth of transport activity has impacted negatively to city residents and environment in terms of traffic congestion, air and noise pollution, as well as, road damage. Among the potential interventions, urban distribution center (UDC) appears to be the most common alternative to minimize urban transport activity by consolidating freight movements. Urban distribution center (UDC) is a logistics facility that is placed relatively close to a specific place such as shopping centers, airports, downtown, or the entire urban area (Allen, Browne, Woodburn \& Leonardi, 2012). The purpose of the implementation of the UDC is to avoid poor utilization of goods transport to urban areas and reduce congestion by consolidating freight movements. However, the effectiveness of UDC to handle urban transport depends, to a great extent, on the location of the UDC (Sopha, Asih, Pradana, Gunawan \& Karuniawati, 2016).

Yogyakarta Special Region Province, Indonesia, is taken up as a studied case. Currently, the province has no strict regulation for freight transport. The freight transport in the province are managed independently by individual companies which are mainly private. The number of individual private companies has been noticeably increasing, and so are the generated freight transports. It was recorded that the number of private chain stores has been increased by $125 \%$ during 2009-2013. Regulations of freight delivery system such as delivery time restriction and structured delivery zones can be effectively implemented by the establishment of distribution center. Previous researches, e.g., Shao, Chen and Wei (2009), Awasthi and Chauhan (2011), have indicated that UDC has contributed to cost savings, efficient flow of goods, increased income for private companies, and traffic reduction in a densely populated area.

In 2008, the local government of Yogyakarta initiated to establish UDC as a temporary storage area to collect the goods from outside the province and then distribute the goods on a scheduled basis with optimal truck utilization. The local government of Yogyakarta has prepared the area for potential UDC, so-called Jogja Inland Port, which is located in Sedayu (Bantul district). The location was selected by the local government based on feasibility study which considered land availability and adequacy of multi-modal transport. The progress of UDC establishment has, however, been hampered due to doubt in the effectiveness of the potential UDC. Private companies has so far been reluctant to participate in Jogja Inland Port. Therefore, it is of importance to address uncertainty in UDC location decision-making because, in reality, decision makers are usually uncertain about decision parameters and unable to define the parameters precisely.

The present paper therefore proposes a framework of integrating weighted GIS data and fuzzy MCDM (Multi Criteria Decision Making) technique as an improved method for evaluating and selecting the appropriate location for Urban Distribution Center. The paper proposes two steps of analysis; i.e. spatial analysis to generate alternative locations using weighted Geographical Information System (GIS) data, and multi-criteria decision-making to select the best UDC location using fuzzy MCDM. Pairwise comparison is used in the first step to determine potential areas and generate alternative locations, while Fuzzy Technique for Order of Preference by Similarity to Ideal Solution (Fuzzy TOPSIS) is used in the second step to select the best alternative location.

The problem raised in the present study is usually known as "location problem" in supply chain and logistics field. Location-selection problem is one of strategic decision makings involving multiple stakeholders with conflicting interests and various criteria which need to be simultaneously evaluated. The location problem can be addressed by two approaches, i.e. ranking approach and optimization approach. Multi-criteria decision analysis, fuzzy multi-criteria decision-making, e.g. Chou and Chang (2009), Durbach and Stewart (2012), falls within the ranking 
approach, whereas network location model and integer programming models are categorized as the optimization approach. The optimization method is usually applied for certain location problem, whereas the ranking approach, commonly used at macro analysis. The ranking approach is used when there exists a set of locations (alternatives) that need to be examined using a set of criteria independent of each other. The selected location is one that performs best with respect to all criteria. Nevertheless, most of literatures of location problem seems to be dominated by optimization which set the location problem in certain environment.

On the other hand, Agrebi, Abed and Omri (2015) who surveyed literatures of UDC location in both certain and uncertain settings has indicated the growing interest of addressing uncertainty in UDC location selection. Given the multiple criteria and stakeholders in location selection problem, Multiple Criteria Decision-Making (MCDM) such as Simple additive Weighting (SAW), Techniques for Order Preference by Similarity to the Ideal Solution (TOPSIS), Elimination et Choice Translating Reality (ELECTRE), Analytical Hierarchy Process (AHP), The Simple Multi Attribute Rating Techniques (SMART), and Analytic Network Process (ANP) has been widely used to select the best alternatives from the feasible alternatives given multiple and conflicting criteria and stakeholders. Furthermore, to deal with uncertain and vagueness of decision-makings, MCDM is generally combined with fuzzy set theory, characterized by a membership function between 0 and 1 . To express linguistic terms of subjective judgment in a quantitative manner, Zadeh (1965) proposed fuzzy set (FS) which was represented using Fuzzy numbers (FN), e.g., triangular FN, trapezoidal FN, Gaussian FN. Atanassov (1986) has then theoretically developed Intuitionistic Fuzzy Number (IFN) which considers both membership function (a degree an element belongs to a particular set) and non-membership function (a degree an element does not belongs to a particular set). The IFNs is further enriched to use interval values instead of exact numbers for membership and non-membership functions, so-called Interval-Valued Intuitionistic Fuzzy Numbers (IVIFNs).

Based on supply chain and logistics literatures published until 2015, the most frequent MCDM methods in the literatures are AHP (19.5\%) and TOPSIS (12.4\%) (Castro \& Parreiras, 2018). Furthermore, combined/hybrid MCDM approaches are more frequent than single method because combined method seems to be a solution to outdo weaknesses of individual MCDM methods. The combination of MCDM method with fuzzy such as fuzzy AHP and fuzzy TOPSIS appears to be the most mutual way to handle uncertainty. Seyedmohammadi, Samadian, Kafarzadeh, Ghorbanim and Shahbazi (2018) has demonstrated that fuzzy TOPSIS (hybrid MCDM) was found to be more accurate than SAW or TOPSIS (single MCDM) because the hybrid MCDM addresses the uncertainty and twin comparing alternatives. When compared to fuzzy AHP, fuzzy TOPSIS was found to perform better than Fuzzy AHP with respect to changes of alternatives and criteria, agility, and number of criteria and alternative suppliers in supplier selection problem (Junior, Osiro \& Carpinetti, 2014). Ertugrul and Karakasoglu (2008) exhibited that the ranking results of fuzzy AHP is the same as those of fuzzy TOPSIS when decision-makers are consistent in determining data. As the UDC location problem involves ten criteria and multiple stakeholders, fuzzy TOPSIS is preferred to fuzzy AHP to avoid internal inconsistency. The fuzzy TOPSIS has been extensively implemented across various application areas and it is particularly applied in solving problems involving both group decision making and uncertainty such as supplier selection (Junior et al., 2014; Chen, Lin \& Huang, 2006), facility location decision making (Ertugrul \& Karakasoglu, 2008), performance evaluation of reverse logistics (Han \& Trimi, 2018), stock exchange (Hatami-Marbini \& Kangi, 2017), and cultivation priority planning (Seyedmohammadi et al., 2018).

Another type of hybrid MCDM is to integrate spatial aspect by coupling MCDM with Geographical Information System (GIS). The hybrid GIS-MCDM has been mostly implemented in land suitability analysis such as Dhiman, Kalbar and Inamdar (2018), Kazemi and Akinci (2018). The combination of AHP-GIS appears to be the most common hybrid of spatial MCDM. MCDM which incorporates preferences of decision makers derives weights than can be used to transform geographical data into information for decision-making in the form of area index. It is argued that by incorporating quantitative geographical data with qualitative data of decision makers' preference, a better decision can be obtained.

As the majority of fuzzy TOPSIS applications mainly focus on ranking the priority of predefined options or planning scenarios, the fuzzy TOPSIS can be extended further by taking into account spatial aspect to provide insights on the spatial extent of the options. The present paper therefore proposes a framework of hybrid 
spatial-fuzzy multi-criteria decision-making. The framework integrates GIS data and MCDM techniques as an improved method for evaluating UDC options. The present study contributes not only to demonstrate the proposed framework incorporating both spatial and uncertainty aspects in facility location planning, but also to provide empirical justification of the ineffective plan on Jogja Inland Port. The present study gives insights to the local government to consider multi criteria, multiple stakeholders, uncertainty, and spatial feasibility, whereas the previous study dealt with economic analysis assuming certain environment where all decision parameters are known and fixed.

The rest of the paper is organized as follows: this section introduces the case background. Section Two presents theoretical background, which is followed by the proposed framework and its application toward the studied case, sensitivity analysis to evaluate robustness of the results, and comparative analysis to evaluate consistency of the results in Section Three. Section Four presents discussion, before closing with Conclusion in Section 5.

\section{Basic Concepts of Fuzzy Numbers and Multi Criteria Decision Making (MCDM)}

This section presents basic concepts of fuzzy set theory covering Triangular Fuzzy Numbers (TFN) and Intuitionistic Fuzzy Numbers (IFNs), and MCDM techniques of AHP and TOPSIS which are used in the present study.

\subsection{Fuzzy Set}

Fuzzy set theory is a powerful tool to handle ambiguity, uncertainty, and imprecise input or knowledge among decision makers (Dernoncourt, 2013). Particularly, fuzzy logic is used to tackle problem areas which combine numerical (mathematical) with symbolic/linguistic solutions. Therefore, when system knowledge is available in linguistic and/or numerical terms, fuzzy logic may be very helpful in the design of a solution. Fuzzy has been widely used in location problem. For instance, Chen-Tung (2001) used fuzzy in selecting UDC location, Hu, Wu and Cai (2009) integrated fuzzy set theory, factor rating system, and simple addictive weighting for alternative locations to evaluate distribution center facilities, Awasthi and Chauhan (2011) applied the method to select location of distribution centers, and Kim, Chung, Kun and Kim (2013) used the method to determine best sites for treated wastewater instream use in an urban watershed.

Fuzzy can transform information that is uncertain as linguistic information into fuzzy numbers that can be processed into arithmetic operations. Fuzzy sets are sets with elements having degree of membership. The membership of the elements in a set belongs to the closed interval between 0 and 1 where 0 represents non-membership and 1 represents full membership. Different types of fuzzy such as triangular FN, trapezoidal FN and Gaussian FN can be used for different situations. The present study uses Triangular Fuzzy Number (TFN) which is relatively simple to compute.

A triangular fuzzy number is represented as a triplet $\tilde{a}=(\mathrm{a}, \mathrm{b}, \mathrm{c})$ as shown in Figure 1.

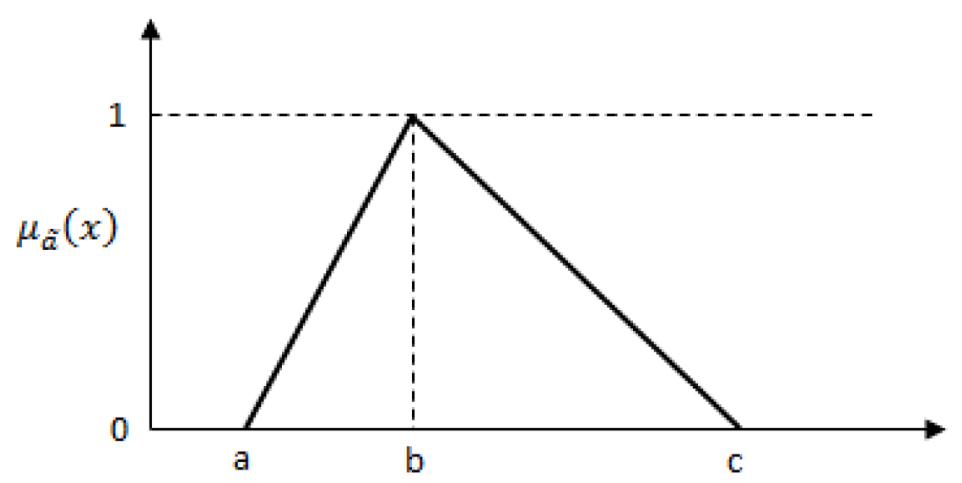

Figure 1. Triangular fuzzy number $\tilde{a}$ 
The membership function $\mu_{\hat{a}}(x)$ is defined as follows,

$$
\mu_{\tilde{a}}(x)=\left\{\begin{array}{c}
0, x<a \\
\frac{x-a}{b-a}, a \leq x \leq b \\
\frac{c-x}{c-b}, b \leq x \leq c \\
0, x>c
\end{array}\right.
$$

Between the two TFNs $\tilde{a}_{1}=(\mathrm{a} 1, \mathrm{~b} 1, \mathrm{c} 1)$ and $\tilde{a}_{2}=(\mathrm{a} 2, \mathrm{~b} 2, \mathrm{c} 2)$, the Euclidean distance between them is calculated by:

$$
d\left(\tilde{a}_{1}, \tilde{a}_{2}\right)=\sqrt{\frac{1}{3}\left[\left(a_{1}-a_{2}\right)^{2}+\left(b_{1}-b_{2}\right)^{2}+\left(c_{1}-c_{2}\right)^{2}\right]}
$$

Another way to represent fuzziness is by using Intuitionistic Fuzzy Numbers (IFNs) proposed by Atanassov (1986) who extended the idea of fuzzy set of the traditional 0-1 logic (Zadeh, 1965). IFNs treats vague information by considering membership function (a degree an element belongs to a particular set) and non-membership function (a degree the element does not belong to the set) and hesitation degree. This way, IFNs handles impreciseness, vagueness, and uncertainties more efficient as it minimizes the imprecision degree. An IFNs A in a finite set $\mathrm{X}$ can be defined as:

$$
A=\left\{<x, \mu_{A}(x), v_{A}(x)>\mid x \in X\right\}
$$

Where $\mu_{A}: X \rightarrow[0,1], v_{A}: X \rightarrow[0,1]$ and $0 \leq \mu_{A}(x)+v_{A}(x) \leq 1 \quad \forall x \in X \cdot \mu_{A}(x)$ and $v_{A}(x)$ denotes the degree of membership and the degree of non-membership of $x$ to $A$ respectively. For each IFNs $A$ in $X$, hesitation degree is defined as:

$$
\pi_{A}(x)=1-\mu_{A}(x)-v_{A}(x)
$$

For instance, an IFN $[0.55,0.4]$ represents membership $\mu=0.55$, non-membership $v=0.4$, and hesitation degree of $\pi=0.05$.

\subsection{Multi-Criteria Decision Making (MCDM)}

\subsubsection{Analytic Hierarchy Process (AHP)}

AHP developed by Saaty (1980) has been the most popular MCDM method in literatures (Castro \& Parreiras, 2018). The AHP is based on pairwise comparison of criteria in order to determine weights and evaluates alternatives. The AHP is suitable to solve problems in a hierarchical structure and widely used for comparisons, weighting, and rankings. The present study particularly applies the AHP to derive weight of spatial criteria in selecting facility location. Using AHP procedure (Saaty, 1980), the pairwise comparison matrix is conducted to determine the relative importance of the criteria and eventually the weight of each criterion. In each pair of attributes, decision makers will, based on subjective judgment, specify on how important a criterion is when compared to another criterion using 9-point Likert-scale (see Table 1) to quantify the importance. Scale 1 refers to that the two criteria being compared are equally important and scale 9 indicates that one criterion is absolutely important over another. The pairwise comparison compares each factor to another so that the value of relative importance of each criterion can be determined quantitatively. 


\begin{tabular}{|c|c|}
\hline Scale of importance & Verbal judgment of Performance \\
\hline 1 & Equally importance \\
\hline 3 & Moderate importance \\
\hline 5 & Strong importance \\
\hline 7 & Extreme importance \\
\hline 9 & Extremely more importance \\
\hline $2,4,6,8$ & Intermediate value between adjacent scale value \\
\hline
\end{tabular}

Table 1. Importance scale used in pairwise comparison

If criterion $i$ when compared to criterion $j$ has the value of 2 , criterion $j$ has therefore the reciprocal value, i.e., 0.5 when compared to criterion i. Table 2 shows the application of the rule. After all comparison values are evaluated, the importance of each criterion can be examined using Geometric Mean Method using Equation (5),

$$
r_{j}=\prod_{j=1}^{n}\left(c_{i j}\right)^{1 / n}
$$

Where $c_{i j}$ is the importance ratio between criterion $i$ and criterion $j, n$ is the number of criteria, and $r_{j}$ is geometric mean of criterion $j$. Weight of criteria $\left(w_{j}\right)$ are calculated using Equation $(6)$ as the following,

$$
w_{j}=\frac{r_{j}}{\Sigma_{j} r_{j}}
$$

However, inconsistency may occur. To ensure that the results are consistent, the consistency test is conducted by calculating the consistency ratio (CR). The results are consistent if the CR value is less or equal to 0.10 . The procedure for evaluating consistency ratio is as the following (see Saaty, 1980, for details).

$$
\begin{gathered}
\lambda_{\text {max }}=\frac{1}{n} \sum_{i=1}^{n} \frac{(C \cdot w)_{i}}{w_{i}} \\
C I=\frac{\lambda_{\max }-n}{n-1} \\
C R=\frac{C I}{R I}
\end{gathered}
$$

where $\mathrm{n}$ is matrix size, CI is consistency index, and RI is random index which is acquired from Saaty (1980). The value of RI is 0.58 for the matrix size of 3 . Despite its simplicity, the AHP has a limitation when it comes to large scale of problem. As the problem scale increases, the potential internal consistency also increases.

\subsubsection{Technique for Order of Preference by Similarity to Ideal Solution (TOPSIS)}

TOPSIS introduced by Hwang and Yoon (1981) is one of the most well-known classical MCDM approaches. The TOPSIS has simple computation process and has high flexibility. The TOPSIS method is applied to tackle multiple-attribute decision making in which the preference is not defined precisely. The principle of TOPSIS method is that the positive ideal alternative is that with the best values for all attributes, whereas the negative ideal alternative is that with all of the worst attribute values. Consequently, the TOPSIS solution is the alternative with the shortest distance to Positive Ideal Solution (PIS) and the farthest distance to Negative Ideal Solution (NIS). The TOPSIS has been widely applied in various fields such as location planning, supplier selection, product design, human resource management, etc. 


\section{Proposed Framework to Evaluate UDC Options}

This section presents the proposed framework and demonstrates its application to the UDC location for Yogyakarta Special Region Province. The framework comprises two steps: generation of alternative locations using weighted GIS data, and selection of the best location of UDC using Fuzzy TOPSIS. The framework has incorporated spatial feasibility, uncertainty, multi criteria, and multiple stakeholders with conflicting goals.

\subsection{Generation of Alternative Locations using Weighted GIS Data}

The overall aim of this section is to identify potential areas for UDC. A set of semi-structured interviews with warehousing and logistics expert, freight transport expert, and the local government was conducted to explore important factors in identifying potential areas for the UDC. Based on the interviews, it was found that land availability, population density and land-ownership were of importance in selecting the potential areas for the UDC on a general level. Land availability refers to the available space, whereas land-ownership refers to the legal ownership of the land. In Yogyakarta Special Region Province, lands are owned by government (public), Yogyakarta sultanate (private), and ordinary people (private). It is of course much easier to build UDC in government-owned land than private-owned land.

AHP was used to determine weights derived from expert and local government knowledge in a spatial context. Following pairwise comparison of Saaty (1980), the local government and experts were then asked to determine the relative importance of the factors. In each pair of attributes, decision makers will specify on how important a criterion is when compared to another criterion using 9-point scale as specified in Table 1. The importance of the criteria is based on subjective judgment. Consequently, using AHP procedure, the value of relative importance of each criterion can be determined quantitatively. After the importance weights of all criteria have been obtained, the spatial data is then weighted to get aggregated spatial values by multiplying the average weight and associated spatial data. ArcGIS 10 software is used to calculate the aggregated spatial value. The weighted geospatial datasets were thus used to identify potential areas for UDC. Table 2 shows the pairwise comparison matrix which represents the relative importance between criteria based on subjective judgment of both the local government and the expert.

Using Equation (5) - Equation (9), acceptable weights from both the local government and the expert were calculated and shown in Table 3. The results indicate that the consistency ratio are $0.069(6.9 \%)$ and $0.025(2.5 \%)$ which are less than the allowed limit consistency ratio of $10 \%$.

The results show that land availability appears to be most important criterion, followed by land-ownership, and population density. The order of importance weight by local government is in agreement with that by the experts. However, land-ownership is given higher weight and land availability is given lower weight by the expert than those by the local government.

The obtained weights between the local government and the expert are then averaged and used to weigh spatial data of land availability, land-ownership, and population density, using ArcGIS 10. Figure 2 shows the potential areas for the UDC to be presented as a heatmap in which green areas indicate the most potential areas and red areas indicate the non-potential areas for the UDC.

\begin{tabular}{|l|r|r|r|r|r|r|}
\hline \multirow{2}{*}{} & \multicolumn{3}{|c|}{ The Local government } & \multicolumn{3}{c|}{ The Experts } \\
\cline { 2 - 7 } & \multicolumn{1}{|c|}{$\begin{array}{c}\text { Land } \\
\text { availability }\end{array}$} & $\begin{array}{c}\text { Population } \\
\text { density }\end{array}$ & $\begin{array}{c}\text { Land- } \\
\text { ownership }\end{array}$ & $\begin{array}{c}\text { Land } \\
\text { availability }\end{array}$ & $\begin{array}{c}\text { Population } \\
\text { density }\end{array}$ & $\begin{array}{c}\text { Land- } \\
\text { ownership }\end{array}$ \\
\hline Land availability & 1 & 9 & 7 & 1 & 9 & 3 \\
\hline Population density & 0.111 & 1 & 0.333 & 0.111 & 1 & 0.2 \\
\hline Land-ownership & 0.143 & 3 & 1 & 0.333 & 5 & 1 \\
\hline
\end{tabular}

Table 2. Pairwise comparison matrix 


\begin{tabular}{|c|c|c|c|c|}
\hline & \multicolumn{2}{|c|}{ Local government } & \multicolumn{2}{|c|}{ Expert } \\
\hline & Geometric Mean ( $x$ ) & Weight (w) & Geometric Mean $(r)$ & Weight (w) \\
\hline Land availability & 3.979 & 0.785 & 3.000 & 0.672 \\
\hline Population density & 0.333 & 0.066 & 0.281 & 0.063 \\
\hline Land-ownership & 0.754 & 0.149 & 1.186 & 0.265 \\
\hline Sum & 5.066 & 1.000 & 4.467 & 1.000 \\
\hline$\lambda_{\max }$ & & 3.080 & & 3.029 \\
\hline Random Index (RI) & & 0.580 & & 0.580 \\
\hline Consistency Index (CI) & & 0.040 & & 0.015 \\
\hline Consistency Ratio (CR) & & 0.069 & & 0.025 \\
\hline
\end{tabular}

Note: Numerical example for local government

Using Equation (5): geometric mean for land availability, $r=\sqrt[3]{(1 \times 9 \times 7)}=3.979$

Using Equation (6): weight for land availability, $w=3.979 / 5.066=0.785$

Using Equation (7): $\lambda_{\max }=((1 \mathrm{x} 0.785+9 \mathrm{x} 0.066+7 \mathrm{x} 0.149) / 0.785+(0.111 \times 0.785+1 \mathrm{x} 0.066+0.333 \times 0.149) / 0.066+$ $(0.143 \times 0.785+3 \times 0.066+1 \times 0.149) / 0.149)) / 3=3.080$

Using Equation (8): $C I=\frac{\lambda_{\max }-n}{n-1}=\frac{3.080-3}{3-1}=0.040$

Using Equation (9): $C R=\frac{C I}{R I}=\frac{0.04}{0.58}=0.069$

Table 3. Geometric mean and weights of determinants factors for potential areas for UDC

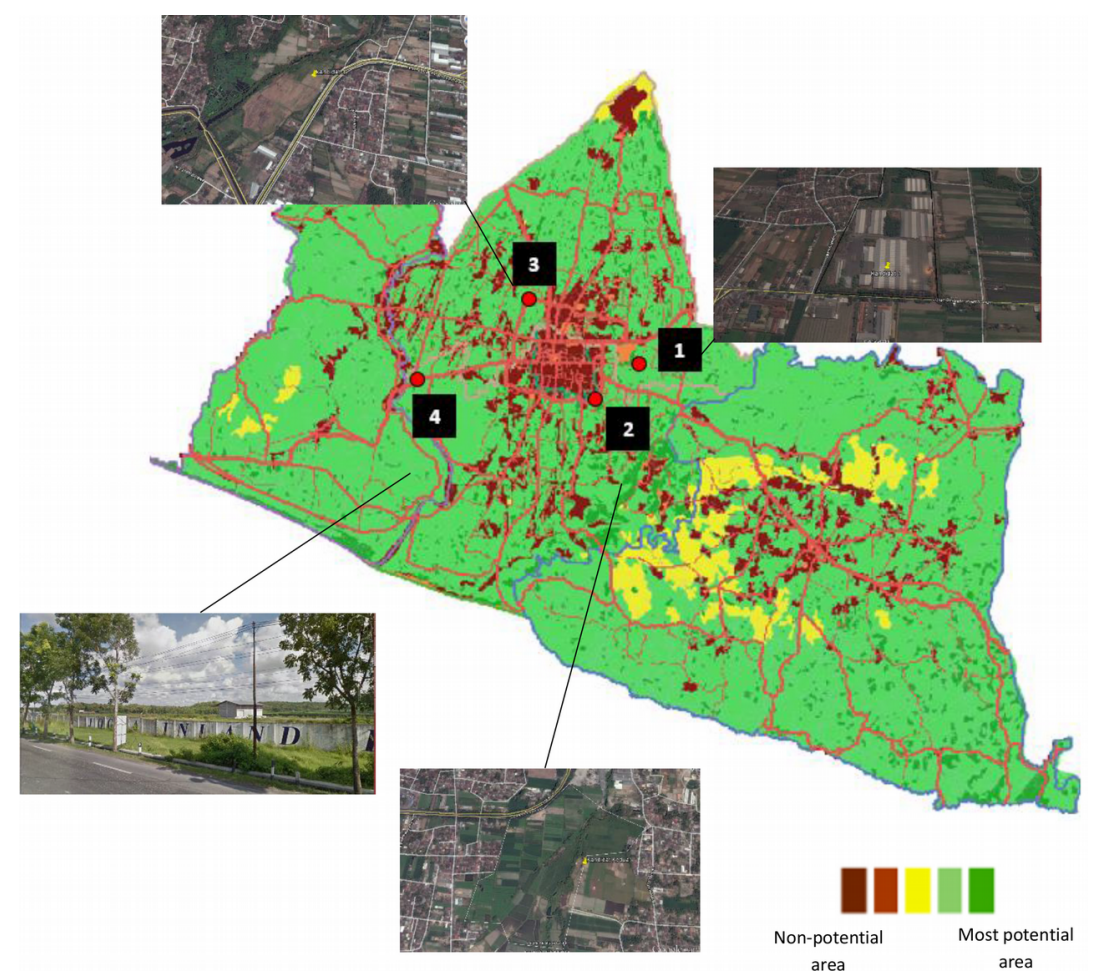

Figure 2. Heatmap of potential areas for the UDC and selected UDC location in Yogyakarta Special Region Province

Based on the aforementioned potential areas which is presented as a heatmap in Figure 2, alternative specific locations for the UDC were selected. In order to select specific locations, the Minister Decree No. 31 of 1995 on Road Transport Terminal (section 29), which stated that distribution center should be located on freight transport network, next to arterial road, and has a minimum area of 3 hectares, is therefore used as basic requirement to choose other alternative locations to be evaluated in the second stage. The selected alternative locations are as the following. Alternative 1 (A1) located in Berbah (Sleman district) has been used as a joint warehouse managed by a 
group of private companies. Alternative 2 (A2) located in Wirokerten (Bantul district) was selected because it is located at the center of Yogyakarta Special Region Province and closer to the city center than A1. Alternative 3 (A3) located in Trianggo (Sleman district) has been used as a distribution center owned by one of the dominating private chain stores in Yogyakarta Special Region Province. Alternative (A4) located in Argosari (Bantul district) is the location of Jogja Inland Port that has been prepared by the local government for the UDC. The locations of the four alternatives are shown in Figure 2. To summarize, two location candidates, i.e., A1 and A4, are outside the area of the city and other two candidates, i.e., A2 and A3, are in the circumference area of the city (closer to the city center).

\subsection{Evaluation of Alternative UDC Locations Using Fuzzy TOPSIS}

The second step involves the selection of location criteria and the evaluation of selected specific UDC location against the selected criteria. To incorporate multi-criteria and multiple decision makers, as well as, to deal with uncertainty with respect to decision parameters and alternative set, fuzzy set theory is then combined with the TOPSIS. The present study uses Fuzzy TOPSIS. It is expected that, by using Fuzzy TOPSIS, the best alternative location of the UDC can be examined by quantifying uncertainty and exposing more accurate calculation with a more plausible explanation.

Previous study of Jogja Inland Port by the local government used two criteria, i.e., land availability and adequacy of multi-modal transport, to assess its feasibility. The present study has therefore expanded the two previous criteria with other potential criteria obtained from literature review and interviews. Literature review was conducted to list potential criteria relevant to the study context. Based on set of discussions with practitioners, experts in cargo terminal, and the local government, ten criteria were identified to be relevant and, consequently, used in the study (see Table 4). It is found out that the criteria are also in line with those of Awasthi and Chauhan (2011) and Agrebi et al. (2015).

Following Anand, Quak, van Duin and Tavasszy (2012) who suggested that modelling efforts should consider inputs from all stakeholders, four decision-makers who represent the local government of Yogyakarta Province (D1), logistics/transportation expert (D2) and two practitioners (one from distribution company - D3, and one from food company - D4) were involved in the study.

The four selected locations specified in Section 3.1 were then evaluated using fuzzy TOPSIS by the four decision makers. As the study implements fuzzy TOPSIS, the TOPSIS procedure is modified to include fuzzy set as the following.

Assuming that there are $\mathrm{m}$ potential location candidates called $A=\left\{A_{1}, A_{2}, \ldots, A_{m}\right\}$ which are evaluated against $\mathrm{n}$ criteria denoted $C=\left\{C_{1}, C_{2}, \ldots, C_{n}\right\}$ weighted using $\mathrm{w}_{\mathrm{j}}(j=1,2, \ldots, n)$. The performance ratings by decision maker $D_{k}(k=1,2, \ldots, l)$ for each alternative $A_{i}(i=1,2, \ldots, m)$ with respect to criteria $C_{j}(j=1,2, \ldots, n)$ are denoted by $\tilde{x}_{i j k}(i=1,2, \ldots, m ; j=1,2, \ldots, n ; k=1,2, \ldots, l)$.

Step 1. Create a performance decision matrix consisting of $m$ alternatives and $\mathrm{n}$ criteria.

Fuzzy ratings of $w_{j}$ and $\tilde{x}_{i j k}$ follow triangular fuzzy numbers (TFN) $\left(a_{k}, b_{k}, c_{k}\right)$. Using Triangular Fuzzy Number as specified in Equation (1), linguistic terms for alternatives and criteria are shown in Table 5. The decision makers have then provided linguistic assessment for the criteria as shown in Table 6 and linguistic assessment for alternatives with respect to each criterion as shown in Table 7. 


\begin{tabular}{|l|l|}
\hline \multicolumn{1}{|c|}{ Criteria } & \multicolumn{1}{c|}{ Definition } \\
\hline Accessibility (C1) & Access by public and private transport (road network) \\
\hline Security (C2) & Risk associated to theft, accidents \\
\hline Connectivity-multimodal transport (C3) & Connectivity with other transport modes \\
\hline Costs (C4) & Land cost, building cost, and operational cost \\
\hline Environmental impact (C5) & Air and noise pollution \\
\hline Proximity to customers (C6) & Distance of the location to customers \\
\hline Proximity to suppliers (C7) & Distance of the location to suppliers \\
\hline Resource availability (C8) & Availability of labor and natural resources \\
\hline Expansion possibility (C9) & The possibility to expand (social acceptance) \\
\hline Service quality (C10) & Ability to deliver timely and reliably \\
\hline
\end{tabular}

Table 4. Criteria for Location Evaluation

\begin{tabular}{|l|c|c|}
\hline \multirow{2}{*}{\multicolumn{1}{|c|}{ Linguistic term }} & \multicolumn{2}{c|}{ Membership function } \\
\cline { 2 - 3 } & Alternative rating & Criterion rating \\
\hline Very Poor (VP)/Very Low (VL) & $(1,1,3)$ & $(1,1,3)$ \\
\hline Poor (P)/Low (L) & $(1,3,5)$ & $(1,3,5)$ \\
\hline Fair (F)/Medium (M) & $(3,5,7)$ & $(3,5,7)$ \\
\hline Good (G)/High (H) & $(5,7,9)$ & $(5,7,9)$ \\
\hline Very Good (VG)/Very High (VH) & $(7,9,9)$ & $(7,9,9)$ \\
\hline
\end{tabular}

Table 5. Linguistic terms for alternatives and criteria

\begin{tabular}{|l|c|c|c|c|}
\hline \multirow{2}{*}{\multicolumn{1}{c|}{ Criteria }} & \multicolumn{4}{c|}{ Decision maker } \\
\cline { 2 - 5 } & D1 & D2 & D3 & D4 \\
\hline Accessibility (C1) & VH & M & H & VH \\
\hline Security (C2) & VH & H & H & H \\
\hline Connectivity - multimodal transport (C3) & VH & H & H & VH \\
\hline Costs (C4) & H & M & M & M \\
\hline Environmental impact (C5) & H & H & H & M \\
\hline Proximity to customers (C6) & VH & M & H & H \\
\hline Proximity to suppliers (C7) & H & H & H & H \\
\hline Resource availability (C8) & M & H & M & M \\
\hline Expansion possibility (C9) & M & H & H & M \\
\hline Service quality (C10) & H & H & H & H \\
\hline
\end{tabular}

Table 6. Linguistic assessment for the criteria

\begin{tabular}{|c|c|c|c|c|c|}
\hline \multirow{2}{*}{ Criteria } & \multirow{2}{*}{ Alternatives } & \multicolumn{5}{|c|}{ Decision maker D } \\
\cline { 3 - 6 } & & D1 & D2 & D3 & D4 \\
\hline \multirow{3}{*}{ C1 } & Alternative 1 & F & VG & G & F \\
\cline { 2 - 6 } & Alternative 2 & G & VG & G & G \\
\cline { 2 - 6 } & Alternative 3 & F & VG & G & F \\
\hline
\end{tabular}




\begin{tabular}{|c|c|c|c|c|c|}
\hline \multirow{2}{*}{ Criteria } & \multirow{2}{*}{ Alternatives } & \multicolumn{4}{|c|}{ Decision maker D } \\
\hline & & D1 & $\mathrm{D} 2$ & D3 & D4 \\
\hline & Alternative 4 & G & VG & G & G \\
\hline \multirow{4}{*}{$\mathrm{C} 2$} & Alternative 1 & G & G & G & G \\
\hline & Alternative 2 & $\mathrm{~F}$ & $\mathrm{P}$ & $\mathrm{P}$ & $\mathrm{P}$ \\
\hline & Alternative 3 & $\mathrm{~F}$ & $\mathrm{P}$ & $\mathrm{F}$ & $\mathrm{F}$ \\
\hline & Alternative 4 & $\mathrm{~F}$ & $\mathrm{~F}$ & G & $\mathrm{F}$ \\
\hline \multirow{4}{*}{ C3 } & Alternative 1 & G & G & G & G \\
\hline & Alternative 2 & G & G & $\mathrm{F}$ & G \\
\hline & Alternative 3 & $\mathrm{~F}$ & VG & G & $\mathrm{F}$ \\
\hline & Alternative 4 & G & VG & G & G \\
\hline \multirow{4}{*}{$\mathrm{C} 4$} & Alternative 1 & G & $\mathrm{F}$ & G & $\mathrm{F}$ \\
\hline & Alternative 2 & G & $\mathrm{F}$ & $\mathrm{P}$ & $\mathrm{F}$ \\
\hline & Alternative 3 & VP & $\mathrm{F}$ & $\mathrm{P}$ & $\mathrm{F}$ \\
\hline & Alternative 4 & G & G & G & G \\
\hline \multirow{4}{*}{$\mathrm{C} 5$} & Alternative 1 & $\mathrm{P}$ & $\mathrm{F}$ & G & G \\
\hline & Alternative 2 & $\mathrm{VP}$ & G & $\mathrm{F}$ & G \\
\hline & Alternative 3 & VP & G & G & G \\
\hline & Alternative 4 & G & $\mathrm{F}$ & G & G \\
\hline \multirow{4}{*}{ C6 } & Alternative 1 & $\mathrm{~F}$ & $\mathrm{~F}$ & G & $\mathrm{F}$ \\
\hline & Alternative 2 & $\mathrm{~F}$ & G & G & $\mathrm{F}$ \\
\hline & Alternative 3 & $\mathrm{~F}$ & G & G & $\mathrm{F}$ \\
\hline & Alternative 4 & $\mathrm{P}$ & G & G & $\mathrm{F}$ \\
\hline \multirow{4}{*}{$\mathrm{C} 7$} & Alternative 1 & G & $\mathrm{F}$ & G & $\mathrm{F}$ \\
\hline & Alternative 2 & $\mathrm{P}$ & $\mathrm{F}$ & $\mathrm{F}$ & $\mathrm{F}$ \\
\hline & Alternative 3 & $\mathrm{P}$ & $\mathrm{F}$ & $\mathrm{F}$ & $\mathrm{F}$ \\
\hline & Alternative 4 & $\mathrm{P}$ & $\mathrm{F}$ & G & G \\
\hline \multirow{4}{*}{$\mathrm{C} 8$} & Alternative 1 & G & G & G & G \\
\hline & Alternative 2 & $\mathrm{~F}$ & G & G & G \\
\hline & Alternative 3 & $\mathrm{~F}$ & G & G & G \\
\hline & Alternative 4 & $\mathrm{~F}$ & G & G & $\mathrm{F}$ \\
\hline \multirow{4}{*}{ C9 } & Alternative 1 & G & G & G & G \\
\hline & Alternative 2 & $\mathrm{P}$ & G & $\mathrm{P}$ & G \\
\hline & Alternative 3 & $\mathrm{P}$ & $\mathrm{F}$ & $\mathrm{F}$ & G \\
\hline & Alternative 4 & G & $\mathrm{F}$ & G & G \\
\hline \multirow{4}{*}{ C10 } & Alternative 1 & G & G & G & $\mathrm{F}$ \\
\hline & Alternative 2 & $\mathrm{~F}$ & G & G & G \\
\hline & Alternative 3 & $\mathrm{~F}$ & $\mathrm{~F}$ & G & G \\
\hline & Alternative 4 & $\mathrm{~F}$ & $\mathrm{~F}$ & G & $\mathrm{G}$ \\
\hline
\end{tabular}

Table 7. Linguistic assessment for alternatives 
After each alternative and each criterion has been assigned a value, the next step was to transform the assessment of linguistic terms to membership functions following Table 5 for each criterion and each alternative as shown in Table 8 and Table 9 respectively.

Aggregated fuzzy weight for criteria (Table 8) and aggregate fuzzy rating for alternatives (Table 9) were examined by averaging the membership functions following Equation (10). Aggregated fuzzy weight for criteria $\left(\widetilde{w}_{j}\right)$ and aggregated fuzzy rating $\left(\widetilde{r}_{i j}\right)$ can be evaluated as:

$$
a=\min _{k}\left\{a_{k}\right\}, b=\frac{1}{K} \sum_{k=1}^{K} b_{k}, c=\max _{k}\left\{c_{k}\right\}
$$

\begin{tabular}{|c|c|c|c|c|c|}
\hline \multirow{2}{*}{ Criteria } & \multicolumn{4}{|c|}{ Decision maker } & \multirow{2}{*}{$\begin{array}{l}\text { Aggregated } \\
\text { Fuzzy Weight }\end{array}$} \\
\hline & $\mathrm{D} 1$ & $\mathrm{D} 2$ & $\mathrm{D} 3$ & D4 & \\
\hline $\mathrm{C} 1$ & $(7,9,9)$ & $(3,5,7)$ & $(5,7,9)$ & $(7,9,9)$ & $(3,7.5,9)$ \\
\hline $\mathrm{C} 2$ & $(7,9,9)$ & $(5,7,9)$ & $(5,7,9)$ & $(5,7,9)$ & $(5,7.5,9)$ \\
\hline C3 & $(7,9,9)$ & $(5,7,9)$ & $(5,7,9)$ & $(7,9,9)$ & $(5,8,9)$ \\
\hline $\mathrm{C} 4$ & $(5,7,9)$ & $(3,5,7)$ & $(3,5,7)$ & $(3,5,7)$ & $(3,6,9)$ \\
\hline $\mathrm{C} 5$ & $(5,7,9)$ & $(5,7,9)$ & $(5,7,9)$ & $(3,5,7)$ & $(5,7,9)$ \\
\hline C6 & $(7,9,9)$ & $(3,5,7)$ & $(5,7,9)$ & $(5,7,9)$ & $(3,7,9)$ \\
\hline $\mathrm{C} 7$ & $(5,7,9)$ & $(5,7,9)$ & $(5,7,9)$ & $(5,7,9)$ & $(5,7,9)$ \\
\hline $\mathrm{C} 8$ & $(3,5,7)$ & $(5,7,9)$ & $(3,5,7)$ & $(3,5,7)$ & $(3,5.5,9)$ \\
\hline C9 & $(3,5,7)$ & $(5,7,9)$ & $(5,7,9)$ & $(3,5,7)$ & $(3,6,9)$ \\
\hline C10 & $(5,7,9)$ & $(5,7,9)$ & $(5,7,9)$ & $(5,7,9)$ & $(5,7,9)$ \\
\hline
\end{tabular}

Note: Numerical example for criterion C1, using Equation (10):

$$
a=\min _{4}\{7,3,5,7\}, b=\frac{1}{4} \sum_{k=1}^{4}(9+5+7+9), c=\max _{4}\{9,7,9,9\}=(3,7.5,9)
$$

\begin{tabular}{|c|c|c|c|c|c|c|}
\hline \multirow{2}{*}{ Criteria } & \multirow{2}{*}{ Alternatives } & \multicolumn{4}{|c|}{ Decision maker } & \multirow{2}{*}{$\begin{array}{l}\text { Aggregate } \\
\text { Fuzzy Rating }\end{array}$} \\
\hline & & D1 & $\mathrm{D} 2$ & D3 & D4 & \\
\hline \multirow{4}{*}{ C1 } & Alternative 1 & $(3,5,7)$ & $(7,9,9)$ & $(5,7,9)$ & $(3,5,7)$ & $(3,6.5,9)$ \\
\hline & Alternative 2 & $(5,7,9)$ & $(7,9,9)$ & $(5,7,9)$ & $(5,7,9)$ & $(5,7.5,9)$ \\
\hline & Alternative 3 & $(3,5,7)$ & $(7,9,9)$ & $(5,7,9)$ & $(3,5,7)$ & $(3,6.5,9)$ \\
\hline & Alternative 4 & $(5,7,9)$ & $(7,9,9)$ & $(5,7,9)$ & $(5,7,9)$ & $(5,7.5,9)$ \\
\hline \multirow{4}{*}{$\mathrm{C} 2$} & Alternative 1 & $(5,7,9)$ & $(5,7,9)$ & $(5,7,9)$ & $(5,7,9)$ & $(3,6.5,9)$ \\
\hline & Alternative 2 & $(3,5,7)$ & $(1,3,5)$ & $(1,3,5)$ & $(1,3,5)$ & $(1,3.5,7)$ \\
\hline & Alternative 3 & $(3,5,7)$ & $(1,3,5)$ & $(3,5,7)$ & $(3,5,7)$ & $(1,4.5,7)$ \\
\hline & Alternative 4 & $(3,5,7)$ & $(3,5,7)$ & $(5,7,9)$ & $(3,5,7)$ & $(3,5.5,9)$ \\
\hline \multirow{4}{*}{ C3 } & Alternative 1 & $(5,7,9)$ & $(5,7,9)$ & $(5,7,9)$ & $(5,7,9)$ & $(5,7,9)$ \\
\hline & Alternative 2 & $(5,7,9)$ & $(5,7,9)$ & $(3,5,7)$ & $(5,7,9)$ & $(3,6.5,9)$ \\
\hline & Alternative 3 & $(3,5,7)$ & $(7,9,9)$ & $(5,7,9)$ & $(3,5,7)$ & $(3,6.5,9)$ \\
\hline & Alternative 4 & $(5,7,9)$ & $(7,9,9)$ & $(5,7,9)$ & $(5,7,9)$ & $(5,7.5,9)$ \\
\hline $\mathrm{C} 4$ & Alternative 1 & $(5,7,9)$ & $(3,5,7)$ & $(5,7,9)$ & $(3,5,7)$ & $(3,6,9)$ \\
\hline
\end{tabular}

Table 8. Aggregate fuzzy weights for criteria 


\begin{tabular}{|c|c|c|c|c|c|c|}
\hline \multirow{2}{*}{ Criteria } & \multirow{2}{*}{ Alternatives } & \multicolumn{4}{|c|}{ Decision maker } & \multirow{2}{*}{$\begin{array}{c}\text { Aggregate } \\
\text { Fuzzy Rating }\end{array}$} \\
\hline & & $\mathrm{D} 1$ & $\mathrm{D} 2$ & $\mathrm{D} 3$ & $\mathrm{D} 4$ & \\
\hline & Alternative 2 & $(5,7,9)$ & $(3,5,7)$ & $(1,3,5)$ & $(3,5,7)$ & $(1,5,9)$ \\
\hline & Alternative 3 & $(1,1,3)$ & $(3,5,7)$ & $(1,3,5)$ & $(3,5,7)$ & $(1,3.5,7)$ \\
\hline & Alternative 4 & $(5,7,9)$ & $(5,7,9)$ & $(5,7,9)$ & $(5,7,9)$ & $(5,7,9)$ \\
\hline \multirow{4}{*}{$\mathrm{C} 5$} & Alternative 1 & $(1,3,5)$ & $(3,5,7)$ & $(5,7,9)$ & $(5,7,9)$ & $(1,5.5,9)$ \\
\hline & Alternative 2 & $(1,1,3)$ & $(5,7,9)$ & $(3,5,7)$ & $(5,7,9)$ & $(1,5,9)$ \\
\hline & Alternative 3 & $(1,1,3)$ & $(5,7,9)$ & $(5,7,9)$ & $(5,7,9)$ & $(1,5.5,9)$ \\
\hline & Alternative 4 & $(5,7,9)$ & $(3,5,7)$ & $(5,7,9)$ & $(5,7,9)$ & $(3,6.5,9)$ \\
\hline \multirow{4}{*}{ C6 } & Alternative 1 & $(3,5,7)$ & $(3,5,7)$ & $(5,7,9)$ & $(3,5,7)$ & $(3,5.5,9)$ \\
\hline & Alternative 2 & $(3,5,7)$ & $(5,7,9)$ & $(5,7,9)$ & $(3,5,7)$ & $(3,6,9)$ \\
\hline & Alternative 3 & $(3,5,7)$ & $(5,7,9)$ & $(5,7,9)$ & $(3,5,7)$ & $(3,6,9)$ \\
\hline & Alternative 4 & $(1,3,5)$ & $(5,7,9)$ & $(5,7,9)$ & $(3,5,7)$ & $(1,5.5,9)$ \\
\hline \multirow{4}{*}{$\mathrm{C} 7$} & Alternative 1 & $(5,7,9)$ & $(3,5,7)$ & $(5,7,9)$ & $(3,5,7)$ & $(3,6,9)$ \\
\hline & Alternative 2 & $(1,3,5)$ & $(3,5,7)$ & $(3,5,7)$ & $(3,5,7)$ & $(1,4.5,7)$ \\
\hline & Alternative 3 & $(1,3,5)$ & $(3,5,7)$ & $(3,5,7)$ & $(3,5,7)$ & $(1,4.5,7)$ \\
\hline & Alternative 4 & $(1,3,5)$ & $(3,5,7)$ & $(5,7,9)$ & $(5,7,9)$ & $(1,5.5,9)$ \\
\hline \multirow{2}{*}{$\mathrm{C} 8$} & Alternative 1 & $(5,7,9)$ & $(5,7,9)$ & $(5,7,9)$ & $(5,7,9)$ & $(5,7,9)$ \\
\hline & Alternative 2 & $(3,5,7)$ & $(5,7,9)$ & $(5,7,9)$ & $(5,7,9)$ & $(3,6.5,9)$ \\
\hline \multirow{2}{*}{$\mathrm{C} 8$} & Alternative 3 & $(3,5,7)$ & $(5,7,9)$ & $(5,7,9)$ & $(5,7,9)$ & $(3,6.5,9)$ \\
\hline & Alternative 4 & $(3,5,7)$ & $(5,7,9)$ & $(5,7,9)$ & $(3,5,7)$ & $(3,6,9)$ \\
\hline \multirow{4}{*}{ C9 } & Alternative 1 & $(5,7,9)$ & $(5,7,9)$ & $(5,7,9)$ & $(5,7,9)$ & $(5,7,9)$ \\
\hline & Alternative 2 & $(1,3,5)$ & $(5,7,9)$ & $(1,3,5)$ & $(5,7,9)$ & $(1,5,9)$ \\
\hline & Alternative 3 & $(1,3,5)$ & $(3,5,7)$ & $(3,5,7)$ & $(5,7,9)$ & $(1,5,9)$ \\
\hline & Alternative 4 & $(5,7,9)$ & $(3,5,7)$ & $(5,7,9)$ & $(5,7,9)$ & $(3,6.5,9)$ \\
\hline \multirow{4}{*}{ C10 } & Alternative 1 & $(5,7,9)$ & $(5,7,9)$ & $(5,7,9)$ & $(3,5,7)$ & $(3,6.5,9)$ \\
\hline & Alternative 2 & $(3,5,7)$ & $(5,7,9)$ & $(5,7,9)$ & $(5,7,9)$ & $(3,6.5,9)$ \\
\hline & Alternative 3 & $(3,5,7)$ & $(3,5,7)$ & $(5,7,9)$ & $(5,7,9)$ & $(3,6,9)$ \\
\hline & Alternative 4 & $(3,5,7)$ & $(3,5,7)$ & $(5,7,9)$ & $(5,7,9)$ & $(3,6,9)$ \\
\hline
\end{tabular}

Note: Numerical example for alternative 1 (A1) with respect to criterion C1 using Equation (10):

$$
a=\min _{4}\{3,7,5,3\}, b=\frac{1}{4} \sum_{k=1}^{4}(5+9+7+5), c=\max _{4}\{7,9,9,7\}=(3,6.5,9)
$$

Table 9. Aggregate fuzzy weights for alternatives

Step 2. Calculate the normalized decision matrix.

For fuzzy TOPSIS, the performance decision value is normalized for the benefit and cost criteria, respectively, as the following,

$$
\tilde{r}_{i j}=\left(\frac{a_{i j}}{c_{j}^{+}}, \frac{b_{i j}}{c_{j}^{+}}, \frac{c_{i j}}{c_{j}^{+}}\right) \& \tilde{r}_{i j}=\left(\frac{a_{j}^{-}}{c_{i j}}, \frac{a_{j}^{-}}{b_{i j}}, \frac{a_{j}^{-}}{a_{i j}}\right)
$$


Where $c_{j}^{+}=\underset{i}{\max }\left\{c_{i j}\right\}, a_{j}^{-}={ }_{i}^{\min }\left\{a_{i j}\right\}$, and $\left(\tilde{r}_{i j}\right)$ represents the TFN normalized performance value.

The aggregate fuzzy rating (Table 9) was then normalized using Equation (11) and presented in Table 10.

\begin{tabular}{|c|c|c|c|c|c|c|}
\hline \multirow{2}{*}{ Criteria } & \multirow{2}{*}{$\boldsymbol{a}_{j}^{-}$} & \multirow{2}{*}{$\boldsymbol{c}_{j}^{+}$} & \multicolumn{5}{|c|}{ Normalized Ratings } \\
\cline { 5 - 8 } & & & $\mathbf{A 1}$ & $\mathbf{A} 2$ & $\mathbf{A 3}$ & $\mathbf{A}$ \\
\hline C1 & 3 & $\mathbf{9}$ & $(0.33,0.72,1)$ & $(0.56,0.83,1)$ & $(0.33,0.72,1)$ & $(0.56,0.83,1)$ \\
\hline C2 & 1 & $\mathbf{9}$ & $(0.33,0.72,1)$ & $(0.11,0.39,0.78)$ & $(0.11,0.5,0.78)$ & $(0.33,0.61,11)$ \\
\hline C3 & 3 & $\mathbf{9}$ & $(0.56,0.78,1)$ & $(0.33,0.72,1)$ & $(0.33,0.72,1)$ & $(0.56,0.83,1)$ \\
\hline C4 & $\mathbf{1}$ & 9 & $(0.11,0.17,0.33)$ & $(0.11,0.2,1)$ & $(0.14,0.29,0.14)$ & $(0.11,0.14,0.2)$ \\
\hline C5 & $\mathbf{1}$ & 9 & $(0.11,0.18,1)$ & $(0.11,0.2,1)$ & $(0.11,0.18,1)$ & $(0.11,0.14,0.2)$ \\
\hline C6 & 1 & $\mathbf{9}$ & $(0.33,0.61,1)$ & $(0.33,0.67,1)$ & $(0.33,0.67,1)$ & $(0.11,0.61,1)$ \\
\hline C7 & 1 & $\mathbf{9}$ & $(0.33,0.67,1)$ & $(0.11,0.5,0.78)$ & $(0.11,0.5,0.78)$ & $(0.11,0.61,1)$ \\
\hline C8 & 3 & $\mathbf{9}$ & $(0.56,0.78,1)$ & $(0.33,0.72,1)$ & $(0.33,0.72,1)$ & $(0.33,0.67,1)$ \\
\hline C9 & 1 & $\mathbf{9}$ & $(0.56,0.78,1)$ & $(0.11,0.56,1)$ & $(0.11,0.56,1)$ & $(0.33,0.72,1)$ \\
\hline C10 & 3 & $\mathbf{9}$ & $(0.33,0.72,1)$ & $(0.33,0.67,1)$ & $(0.33,0.67,1)$ & $(0.33,0.67,1)$ \\
\hline
\end{tabular}

Note: Numerical example for $a_{j}^{-}, c_{j}^{+}$and the normalized ratings for A1 with respect to C1 (benefit) using Equation (11):

$$
c_{j}^{+}=\max _{i}\{9,9,9,9\}=9, \tilde{f}_{i j}=\left(\frac{a_{i j}}{c_{i}^{+}}, \frac{b_{i j}}{c_{i}^{+}}, \frac{c_{i j}}{c_{i}^{+}}\right)=\left(\frac{3}{9}, \frac{6.5}{9}, \frac{9}{9}\right)=(0.33,0.72,1)
$$

Numerical example for $a_{j}^{-}, c_{j}^{+}$and the normalized ratings for A1 with respect to C4 (costs) using Equation (11):

$$
a_{j}^{-}=\min _{i}\{3,1,1,5\}=1, \tilde{r}_{i j}=\left(\frac{a_{i}^{-}}{c_{i j}}, \frac{a_{i}^{-}}{b_{i j}}, \frac{a_{i}^{-}}{a_{i j}}\right)=\left(\frac{1}{g}, \frac{1}{6}, \frac{1}{a}\right)=(0.11,0.17,0.33)
$$

\begin{tabular}{|c|c|c|c|c|c|c|}
\hline \multirow{2}{*}{ Criteria } & \multicolumn{4}{|c|}{ Weighted Normalized Alternatives } & \multirow{2}{*}{$\begin{array}{c}\text { FPIS } \\
\left(A^{+}\right)\end{array}$} & \multirow{2}{*}{$\begin{array}{c}\text { FNIS } \\
\left(A^{-}\right)\end{array}$} \\
\hline & A1 & A2 & A3 & A4 & & \\
\hline $\mathrm{C} 1$ & $(1,5.42,9)$ & $(1.67,6.25,9)$ & $(1,5.42,9)$ & $(1.67,6.25,9)$ & $(9,9,9,9)$ & $(1,1,1,1)$ \\
\hline $\mathrm{C} 2$ & $(1.67,5.42,9)$ & $(0.56,2.92,7)$ & $(0.56,3.75,7)$ & $(1.67,4.58,9)$ & $(9,9,9,9)$ & $(0.56,0.56,0.56,0.56)$ \\
\hline C3 & $(2.78,6.22,9)$ & $(1.67,5.78,9)$ & $(1.67,5.78,9)$ & $(2.78,6.67,9)$ & $(9,9,9,9)$ & $(1.67,1.67,1.67,1.67)$ \\
\hline $\mathrm{C} 4$ & $(0.33,1,3)$ & $(0.33,1.2,9)$ & $(0.43,1.71,9)$ & $(0.33,0.86,1.8)$ & $(9,9,9,9)$ & $(0.33,0.33,0.33,0.33)$ \\
\hline C5 & $(0.56,1.27,9)$ & $(0.56,1.4,9)$ & $(0.56,1.27,9)$ & $(0.56,1,1.8)$ & $(9,9,9,9)$ & $(0.56,0.56,0.56,0.56)$ \\
\hline C6 & $(1,4.28,9)$ & $(1,4.67,9)$ & $(1,4.67,9)$ & $(0.33,4.28,9)$ & $(9,9,9,9)$ & $(0.33,0.33,0.33,0.33)$ \\
\hline $\mathrm{C} 7$ & $(1.67,4.67,9)$ & $(0.56,3.5,7)$ & $(0.56,3.5,7)$ & $(0.56,4.28,9)$ & $(9,9,9,9)$ & $(0.56,0.56,0.56,0.56)$ \\
\hline $\mathrm{C} 8$ & $(1.67,4.28,9)$ & $(1,3.97,9)$ & $(1,3.97,9)$ & $(1,3.67,9)$ & $(9,9,9,9)$ & $(1,1,1,1)$ \\
\hline $\mathrm{C} 9$ & $(1.67,4.27,9)$ & $(0.33,3.33,9)$ & $(0.33,3.33,9)$ & $(1,4.33,9)$ & $(9,9,9,9)$ & $(0.33,0.33,0.33,0.33)$ \\
\hline $\mathrm{C} 10$ & $(1.67,5.06,9)$ & $(1.67,5.06,9)$ & $(1.67,4.67,9)$ & $(1 \cdot 67,4 \cdot 67,9)$ & $(9,9,9,9)$ & $(1.67,1.67,1.67,1.67)$ \\
\hline
\end{tabular}

Table 10. Normalized rating for alternatives

Note: Numerical example for weighted normalized alternative 1 with respect to criterion 1 using Equation (12):

$$
\tilde{v}_{i j}=\tilde{r}_{i j} \times \tilde{w}_{j}=(0.33,0.72,1) x(3,7.5,9)=(1,5.42,9)
$$

Table 11. Weighted normalized alternatives, FPIS dan FPNS

Step 3. Calculate the weighted normalized decision matrix.

$$
\tilde{v}_{i j}=\tilde{r}_{i j} \times \tilde{w}_{j}
$$

Using Equation (12), normalized rating for alternatives (Table 10) was multiplied with aggregated fuzzy weight (Table 8) to obtain weighted normalized alternatives which is presented in Table 11. 
Step 4. Determine the positive ideal solution FPIS $\left(A^{+}\right)$and negative ideal solution NIS $\left(A^{-}\right)$.

The fuzzy positive ideal solutions FPIS $\left(A^{+}\right)$and fuzzy negative ideal solution FNIS $\left(A^{-}\right)$are determined by:

$$
A^{+}=\left(\tilde{v}_{1}^{+}, \tilde{v}_{2}^{+}, \cdots, \tilde{v}_{n}^{+}\right) \quad \& \quad A^{-}=\left(\tilde{v}_{1}^{-}, \tilde{v}_{2}^{-}, \ldots, \tilde{v}_{n}^{-}\right)
$$

Where $\tilde{v}_{j}^{+}=\underset{i}{\max }\left\{\tilde{v}_{i j c}\right\}$ and $\tilde{v}_{j}^{-}=\min _{i}\left\{\tilde{v}_{i j a}\right\}$. Based on Equation (13), Fuzzy Positive Ideal Solution (FPIS) and Fuzzy Negative Ideal Solution (FNIS) were computed and shown in Table 11.

Step 5. Calculate Euclidean distance of each alternative from FPIS and FNIS.

The weighted normalized decisions are then compared to the FPIS and FNIS. Euclidean distances of each alternative from FPIS and FNIS are calculated using Equation (14) as follows:

$$
d_{i}^{+}=\sum_{j=1}^{n} d\left(\tilde{v}_{i j}, \tilde{v}_{j}^{+}\right) \quad \& \quad d_{i}^{-}=\sum_{j=1}^{n} d\left(\tilde{v}_{i j}, \tilde{v}_{j}^{-}\right)
$$

The distances of alternatives for each criteria toward FPIS and FNIS are shown in Table 12.

\begin{tabular}{|l|r|r|r|r|r|r|r|r|r|r|}
\hline & \multicolumn{1}{c|}{ C1 } & \multicolumn{1}{c|}{ C2 } & \multicolumn{1}{c|}{ C3 } & \multicolumn{1}{c|}{ C4 } & \multicolumn{1}{c|}{ C5 } & \multicolumn{1}{c|}{ C6 } & \multicolumn{1}{c|}{ C7 } & C8 & C9 & C10 \\
\hline$d_{v}\left(\mathrm{~A} 1, A^{-}\right)$ & 5.28 & 5.66 & 5.03 & 1.59 & 4.89 & 5.51 & 5.46 & 5.01 & 5.65 & 4.66 \\
\hline$d_{v}\left(\mathrm{~A} 2, A^{-}\right)$ & 5.54 & 3.96 & 4.85 & 5.03 & 4.90 & 5.61 & 4.09 & 4.93 & 5.30 & 4.66 \\
\hline$d_{v}\left(\mathrm{~A} 3, A^{-}\right)$ & 5.28 & 4.15 & 4.85 & 5.07 & 4.89 & 5.61 & 4.09 & 4.93 & 5.30 & 4.57 \\
\hline$d_{v}\left(\mathrm{~A} 4, A^{-}\right)$ & 5.54 & 5.44 & 5.16 & 0.90 & 0.76 & 5.50 & 5.33 & 4.87 & 5.52 & 4.57 \\
\hline$d_{v}\left(\mathrm{~A} 1, A^{+}\right)$ & 5.06 & 4.71 & 3.93 & 7.64 & 6.61 & 5.36 & 4.92 & 5.04 & 4.92 & 4.81 \\
\hline$d_{v}\left(\mathrm{~A} 2, A^{+}\right)$ & 4.52 & 6.12 & 4.62 & 6.73 & 6.56 & 5.25 & 5.93 & 5.46 & 5.98 & 4.81 \\
\hline$d_{v}\left(\mathrm{~A} 3, A^{+}\right)$ & 5.06 & 5.86 & 4.62 & 6.49 & 6.61 & 5.25 & 5.93 & 5.46 & 5.98 & 4.92 \\
\hline$d_{v}\left(\mathrm{~A} 4, A^{+}\right)$ & 4.52 & 4.94 & 3.84 & 8.03 & 7.90 & 5.70 & 5.59 & 5.55 & 5.35 & 4.92 \\
\hline
\end{tabular}

Note: Numerical example for Alternative 1 and criterion C1 using Equation (2):

$$
\begin{aligned}
& d_{v}\left(A 1, A^{-}\right)=\sqrt{\frac{1}{3}\left[(1-1)^{2}+(5.42-1)^{2}+(9-1)^{2}\right]}=5.28 \\
& d_{v}\left(A 1, A^{+}\right)=\sqrt{\frac{1}{3}\left[(1-9)^{2}+(5.42-9)^{2}+(9-9)^{2}\right]}=5.04
\end{aligned}
$$

Table 12. Distance FPIS and FNIS for alternatives

Step 6. Calculate the relative closeness coefficient $\left(C C_{i}\right)$ to the ideal solution.

Closeness coefficient $\left(C C_{i}\right)$ used in this study is the closeness coefficient to determine the ratio of the total distance to the negative ideal solution of the alternative and the total distance to the positive ideal solution and negative ideal solution of the alternative following Equation 15.

$$
C C_{i}=\frac{d_{i}^{-}}{d_{i}^{+}+d_{i}^{-}}
$$

Results of relative closeness coefficient $\left(C C_{i}\right)$ is shown in Table 13. 


\begin{tabular}{|c|c|c|c|c|c|}
\hline & A1 & A2 & A3 & A4 & Ranking Order \\
\hline$d_{i}^{-}$ & 48.74 & 48.87 & 48.74 & 43.60 & \multirow{3}{*}{$\mathrm{A} 1 \succ \mathrm{A} 2 \succ \mathrm{A} 3 \succ \mathrm{A} 4$} \\
\hline$d_{i}^{+}$ & 53.00 & 55.98 & 56.18 & 56.33 & \\
\hline$C C_{i}$ & 0.479 & 0.466 & 0.464 & 0.436 & \\
\hline
\end{tabular}

Note: Numerical example of $d_{i}^{-}, d_{i}^{+}$, and $C C_{i}$ for A1 using Equation (14) and Equation (15):

$$
\begin{aligned}
& d_{i}^{-}=\sum_{j=1}^{n} d\left(\tilde{v}_{i j}, \tilde{v}_{j}^{-}\right)=5.28+5.66+5.03+1.59+4.89+5.51+5.46+5.01+5.65+4.66=48.74 \\
& d_{i}^{+}=\sum_{j=1}^{n} d\left(\tilde{v}_{i j}, \tilde{v}_{j}^{+}\right)=5.06+4.71+3.93+7.64+6.61+5.36+4.92+5.04+4.92+4.81=53 \\
& C C_{i}=\frac{d_{i}^{-}}{d_{i}^{+}+d_{i}^{-}}=\frac{48.74}{53+48.74}=0.479
\end{aligned}
$$

Table 13. Closeness Coefficient $\left(C C_{i}\right)$ of Alternatives

Step 7. Rank preference orders based on relative closeness $\left(C c_{i}\right)$.

The higher the value, the greater the distance $C C_{i}$ alternative to the negative ideal solution, implying that it is closer to the ideal positive solution. It indicates that the alternative with the highest $C C_{i}$ value is the most ideal location as a potential location for the UDC in Yogyakarta Special Region Province. Table 13 shows that, among the alternatives, the first alternative (A1) has the highest $C C_{i}$ value of 0.479 . It implies that Alternative 1 (A1), where a joint warehouse by private companies exists, appears to be the best UDC location, whereas Jogja Inland Port appears to be worst location for establishing the UDC among other examined alternative locations.

\subsection{Sensitivity Analysis}

In order to examine the robustness of the results, sensitivity analysis is conducted. Following Kahraman, Pardalos and Du (2008), sensitivity analysis needs to be conducted when there exists uncertainty in decision parameters. The sensitivity analysis of the present study is carried out to determine the effect of criteria weight. Fifteen experiments were conducted, the first five experiments were set to have similar weight of $(1,1,3),(1,3,5),(3,5,7),(5,7,9)$, and $(7,9,9)$ respectively, for all criteria. The remaining experiments set one of the criteria with the highest weight of $(7,9,9)$ while all the remaining criteria are given the lowest weight $(1,1,3)$. Table 14 and Figure 3 show the results of sensitivity analysis.

Based on the sensitivity analysis results, the first Alternative (A1) seems to be the best alternative for twelve out of fifteen experiments, indicating that the result is relatively robust. Alternative 2 (A2) is the best location when accessibility and proximity to customers are weighted the highest. As expected, Alternative 2 (A2) is better than Alternative 1 (A1) with respect to proximity to customers as discussed earlier. Alternative 3 is the best option when costs becomes very important. It is interesting to note that Jogja Inland Port (Alternative 4 - A4) appears to be the worst alternative in all experiment settings. This may explain unsuccessful effort to establish the UDC in Jogja Inland Port. Since the initiative to establish the UDC in 2008, none of companies has been participated in Jogja Inland Port. The present study suggests that the location of Jogja Inlad Port is not the appropriate location to establish UDC with respect to accessibility, security, connectivity for multimodal transport, costs, environmental impact, proximity to customers, proximity to suppliers, resource availability, expansion possibility, and service quality. 


\begin{tabular}{|c|c|c|c|c|c|}
\hline \multirow{2}{*}{ Experiment } & \multicolumn{4}{|c|}{$C C_{i}$} & \multirow{2}{*}{ Description } \\
\hline & A1 & A2 & A3 & A4 & \\
\hline 1 & 0.423 & 0.421 & 0.420 & 0.385 & All criteria weights $=(1,1,3)$ \\
\hline 2 & 0.456 & 0.452 & 0.452 & 0.419 & All criteria weights $=(1,3,5)$ \\
\hline 3 & 0.472 & 0.461 & 0.459 & 0.428 & All criteria weights $=(3,5,7)$ \\
\hline 4 & 0.483 & 0.466 & 0.464 & 0.435 & All criteria weights $=(5,7,9)$ \\
\hline 5 & 0.522 & 0.492 & 0.488 & 0.465 & All criteria weights $=(7,9,9)$ \\
\hline 6 & 0.443 & 0.457 & 0.441 & 0.426 & $\begin{array}{l}\text { Weight of criteria } 1=(7,9,9) \\
\text { Weight of remaining criteria }=(1,1,3)\end{array}$ \\
\hline 7 & 0.458 & 0.422 & 0.427 & 0.421 & $\begin{array}{l}\text { Weight of criteria } 2=(7,9,9) \\
\text { Weight of remaining criteria }=(1,1,3)\end{array}$ \\
\hline 8 & 0.455 & 0.442 & 0.441 & 0.426 & $\begin{array}{l}\text { Weight of criteria } 3=(7,9,9) \\
\text { Weight of remaining criteria }=(1,1,3)\end{array}$ \\
\hline 9 & 0.387 & 0.424 & 0.428 & 0.343 & $\begin{array}{l}\text { Weight of criteria } 4=(7,9,9) \\
\text { Weight of remaining criteria }=(1,1,3)\end{array}$ \\
\hline 10 & 0.425 & 0.424 & 0.423 & 0.343 & $\begin{array}{l}\text { Weight of criteria } 5=(7,9,9) \\
\text { Weight of remaining criteria }=(1,1,3)\end{array}$ \\
\hline 11 & 0.453 & 0.454 & 0.453 & 0.413 & $\begin{array}{l}\text { Weight of criteria } 6=(7,9,9) \\
\text { Weight of remaining criteria }=(1,1,3)\end{array}$ \\
\hline 12 & 0.456 & 0.428 & 0.427 & 0.413 & $\begin{array}{l}\text { Weight of criteria } 7=(7,9,9) \\
\text { Weight of remaining criteria }=(1,1,3)\end{array}$ \\
\hline 13 & 0.455 & 0.442 & 0.441 & 0.408 & $\begin{array}{l}\text { Weight of criteria } 8=(7,9,9) \\
\text { Weight of remaining criteria }=(1,1,3)\end{array}$ \\
\hline 14 & 0.472 & 0.440 & 0.439 & 0.427 & $\begin{array}{l}\text { Weight of criteria } 9=(7,9,9) \\
\text { Weight of remaining criteria }=(1,1,3)\end{array}$ \\
\hline 15 & 0.443 & 0.442 & 0.438 & 0.408 & $\begin{array}{l}\text { Weight of criteria } 10=(7,9,9) \\
\text { Weight of remaining criteria }=(1,1,3)\end{array}$ \\
\hline
\end{tabular}

Table 14. Results of sensitivity analysis

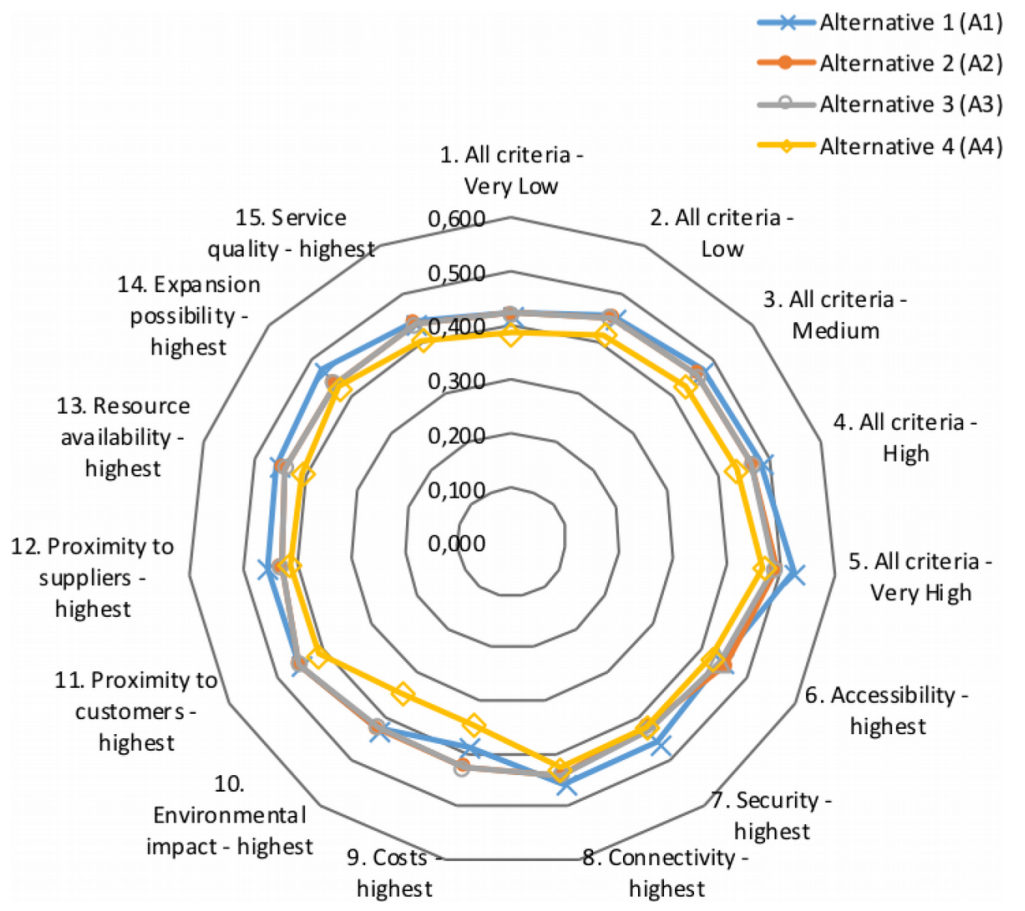

Figure 3. Sensitivity analysis results 


\subsection{Comparative Analysis}

This section aims at performing comparative analysis in order to compare the results of the proposed approach with two other existing approaches under fuzzy environment so that the consistency of the aforesaid results can be justified. Two other different approaches are one focusing on how to represent fuzziness (i.e., Intuitionistic Fuzzy TOPSIS) and one focusing on the developed TOPSIS procedure (i.e., connection number of set pair analysis based on TOPSIS). This sub-section is then divided into two parts: Intuitionistic Fuzzy TOPSIS and Set Pair Analysis based TOPSIS.

\subsubsection{Intuitionistic Fuzzy TOPSIS}

The idea of using intuitionistic fuzzy number in the study has been inspired by Mishra (2016) who evidenced that Fuzzy TOPSIS and Intuitionistic Fuzzy TOPSIS provided different results for rating township development. It is argued that the way to represent fuzziness may lead to different results.

To support the mathematical operation of Intuitionistic Fuzzy TOPSIS, some researchers have developed several aggregation operators such as Intuitionistic Fuzzy Weighted Averaging (IFWA)/Geometric operator by Xu (2007). The principles of IFWA operator are that it weights all given IFNs (by decision makers) by a normalized weight vector, and then aggregates weighted IFNs. Below is the procedure for solving Intuitionistic Fuzzy TOPSIS which is in line to that of Gerogiannis, Fitsilis and Kameas (2011).

Step 1. Create a performance decision matrix consisting of $\mathrm{m}$ alternatives and $\mathrm{n}$ criteria.

Fuzzy ratings for both criteria and alternatives follow Intuitionistic Fuzzy Numbers (IFNs) specified in Equation (3) in the form of $r_{i j}=\left[\mu_{i j}^{(k)}, v_{i j}^{(k)}, \pi_{i j}^{(k)}\right]$. Each decision maker has its weight denoted as $\lambda_{k}(k=1,2, \ldots \ldots, l)$ of $l$ decision makers. The present study assumed that the weights of decision makers were equal so that $\lambda_{1}=\lambda_{2}=\lambda_{3}=\lambda_{4}=0.25$.

Following Intuitionistic Fuzzy Numbers (IFNs) as specified in Equation (3), linguistic terms for criteria (Table 6) and for alternatives (Table 7) were converted to membership functions of IFNs specified in Table 15. Table 16 and Table 17 presents IFNs for criteria and alternatives respectively.

\begin{tabular}{|c|c|c|}
\hline \multirow{2}{*}{ Linguistic term } & \multicolumn{2}{|c|}{ Intuitionistic Membership function } \\
\cline { 2 - 3 } & Alternative rating & Criterion rating \\
\hline Very Poor (VP)/Very Low (VL) & $(0.1,0.9)$ & $(0.1,0.9)$ \\
\hline Poor (P)/Low (L) & $(0.3,0.6)$ & $(0.3,0.6)$ \\
\hline Fair (F)/Medium (M) & $(0.5,0.4)$ & $(0.5,0.4)$ \\
\hline Good (G)/High (H) & $(0.7,0.2)$ & $(0.7,0.2)$ \\
\hline Very Good (VG)/Very High (VH) & $(0.9,0.1)$ & $(0.9,0.1)$ \\
\hline
\end{tabular}

Table 15. Linguistic terms for alternatives and criteria

Aggregated fuzzy weight $\left(\widetilde{\mathfrak{w}}_{j}\right)$ was evaluated using IFWA (Intuitionistic Fuzzy Weighted Averaging) operator as follows $(\mathrm{Xu}, 2007)$.

$$
\begin{aligned}
\tilde{w}_{j} & =I F W A_{\lambda}\left(w_{j}^{(1)}, w_{j}^{(2)}, \ldots \ldots \ldots \ldots \ldots \ldots, w_{j}^{(l)}\right)=\lambda_{1} w_{j}^{(1)} \oplus \lambda_{2} w_{j}^{(2)} \oplus \lambda_{3} w_{j}^{(3)} \oplus \cdots \oplus \lambda_{l} w_{j}^{(l)} \\
& =\left[1-\prod_{k=1}^{l}\left(1-\mu_{j}^{(k)}\right)^{\lambda_{k}}, \prod_{k=1}^{l}\left(v_{j}^{(k)}\right)^{\lambda_{k}}, \prod_{k=1}^{l}\left(1-\mu_{j}^{(k)}\right)^{\lambda_{k}}-\prod_{k=1}^{l}\left(v_{j}^{(k)}\right)^{\lambda_{k}}\right]
\end{aligned}
$$

Table 16 shows a vector of aggregated criteria weight $\left(\widetilde{v}_{j}\right)$ in the form of $\left[\mu_{j}, v_{j}, \pi_{j}\right]$. 


\begin{tabular}{|c|c|c|c|c|c|}
\hline \multirow{2}{*}{ Criteria } & \multicolumn{4}{|c|}{ Decision maker } & \multirow{2}{*}{$\begin{array}{c}\text { Aggregated Fuzzy } \\
\text { Weight }\end{array}$} \\
\cline { 2 - 5 } & D1 & D2 & D3 & D4 & $(0.803,0.168,0.029)$ \\
\hline C1 & $(0.9,0.1,0)$ & $(0.5,0.4,0.1)$ & $(0.7,0.2,0.1)$ & $(0.9,0.1,0)$ & $(0.772,0.168,0.060)$ \\
\hline C2 & $(0.9,0.1,0)$ & $(0.7,0.2,0.1)$ & $(0.7,0.2,0.1)$ & $(0.7,0.2,0.1)$ & $(0.827,0.141,0.032)$ \\
\hline C3 & $(0.9,0.1,0)$ & $(0.7,0.2,0.1)$ & $(0.7,0.2,0.1)$ & $(0.9,0.1,0)$ & $(0.560,0.336,0.104)$ \\
\hline C4 & $(0.7,0.2,0.1)$ & $(0.5,0.4,0.1)$ & $(0.5,0.4,0.1)$ & $(0.5,0.4,0.1)$ & $(0.659,0.238,0.103)$ \\
\hline C5 & $(0.7,0.2,0.1)$ & $(0.7,0.2,0.1)$ & $(0.7,0.2,0.1)$ & $(0.5,0.4,0.1)$ & $(0.741,0.200,0.059)$ \\
\hline C6 & $(0.9,0.1,0)$ & $(0.5,0.4,0.1)$ & $(0.7,0.2,0.1)$ & $(0.7,0.2,0.1)$ & $(0.700,0.200,0.100)$ \\
\hline C7 & $(0.7,0.2,0.1)$ & $(0.7,0.2,0.1)$ & $(0.7,0.2,0.1)$ & $(0.7,0.2,0.1)$ & $(0.560,0.336,0.104)$ \\
\hline C8 & $(0.5,0.4,0.1)$ & $(0.7,0.2,0.1)$ & $(0.5,0.4,0.1)$ & $(0.5,0.4,0.1)$ & $(0.613,0.283,0.104)$ \\
\hline C9 & $(0.5,0.4,0.1)$ & $(0.7,0.2,0.1)$ & $(0.7,0.2,0.1)$ & $(0.5,0.4,0.1)$ & $(0.700,0.200,0.100)$ \\
\hline C10 & $(0.7,0.2,0.1)$ & $(0.7,0.2,0.1)$ & $(0.7,0.2,0.1)$ & $(0.7,0.2,0.1)$ & \\
\hline
\end{tabular}

Table 16. Aggregate fuzzy weights for criteria

Using IFWA, aggregated intuitionistic fuzzy rating $\left(\widetilde{r}_{i j}\right)$ were evaluated using Equation (17) as the following (Xu, 2007):

$$
\begin{aligned}
\tilde{r}_{i j} & =I F W A_{\lambda}\left(r_{i j}^{(1)}, r_{i j}^{(2)}, \ldots \ldots \ldots \ldots \ldots \ldots, r_{i j}^{(l)}\right)=\lambda_{1} r_{i j}^{(1)} \oplus \lambda_{2} r_{i j}^{(2)} \oplus \lambda_{3} r_{i j}^{(3)} \oplus \cdots \oplus \lambda_{l} r_{i j}^{(l)} \\
& =\left[1-\prod_{k=1}^{l}\left(1-\mu_{i j}^{(k)}\right)^{\lambda_{k}}, \prod_{k=1}^{l}\left(v_{i j}^{(k)}\right)^{\lambda_{k}}, \prod_{k=1}^{l}\left(1-\mu_{i j}^{(k)}\right)^{\lambda_{k}}-\prod_{k=1}^{l}\left(v_{i j}^{(k)}\right)^{\lambda_{k}}\right]
\end{aligned}
$$

\begin{tabular}{|c|c|c|c|c|}
\hline \multirow{2}{*}{ Criteria } & \multicolumn{4}{|c|}{ Alternative } \\
\hline & A1 & A2 & A3 & A4 \\
\hline $\mathrm{C} 1$ & $(0.706,0.238,0.056)$ & $(0.772,0.268,0.060)$ & $(0.706,0.238,0.056)$ & $(0.772,0.168,0.060)$ \\
\hline $\mathrm{C} 2$ & $(0.700,0.200,0.100)$ & $(0.356,0.542,0.101)$ & $(0.456,0.443,0.101)$ & $(0.560,0.336,0.104)$ \\
\hline C3 & $(0.700,0.200,0.100)$ & $(0.659,0.238,0.103)$ & $(0.706,0.238,0.056)$ & $(0.772,0.168,0.060)$ \\
\hline $\mathrm{C} 4$ & $(0.613,0.283,0.104)$ & $(0.521,0.372,0.106)$ & $(0.370,0.542,0.088)$ & $(0.700,0.200,0.100)$ \\
\hline $\mathrm{C} 5$ & $(0.579,0.313,0.108)$ & $(0.551,0.346,0.102)$ & $(0.605,0.291,0.104)$ & $(0.659,0.238,0.103)$ \\
\hline C6 & $(0.560,0.336,0.104)$ & $(0.613,0.283,0.104)$ & $(0.613,0.283,0.104)$ & $(0.579,0.313,0.108)$ \\
\hline $\mathrm{C} 7$ & $(0.613,0.283,0.104)$ & $(0.456,0.443,0.101)$ & $(0.456,0.443,0.101)$ & $(0.579,0.313,0.108)$ \\
\hline $\mathrm{C} 8$ & $(0.700,0.200,0.100)$ & $(0.659,0.238,0.103)$ & $(0.659,0.238,0.103)$ & $(0.613,0.283,0.104)$ \\
\hline C9 & $(0.700,0.200,0.100)$ & $(0.542,0.346,0.112)$ & $(0.521,0.372,0.106)$ & $(0.659,0.238,0.103)$ \\
\hline C10 & $(0.659,0.238,0.103)$ & $(0.659,0.238,0.103)$ & $(0.613,0.283,0.104)$ & $(0.613,0.283,0.104)$ \\
\hline
\end{tabular}

Table 17 shows the aggregated ratings in in the form of $\left[\mu_{i j}, v_{i j}, \pi_{i j}\right]$.

Table 17. Aggregated intuitionistic decision matrix

Step 2. Calculate the aggregated weighted intuitionistic fuzzy decision matrix.

The aggregated weighted intuitionistic fuzzy decision matrix (AWIFDM) $\left(\widetilde{v}_{i j}\right)$ is obtained from the aggregated intuitionistic fuzzy decision matrix (Table 17) and criteria weight vector (Table 16). Using the multiplication operator of IFNs following Equation (18), the aggregated intuitionistic fuzzy decision matrix based on 
multiplication of aggregated intuitionistic fuzzy decision matrix and criteria weight vector is as follows (Gerogiannis et al., 2011):

$$
\tilde{v}_{i j}=\tilde{r}_{i j} \otimes \tilde{w}_{j}=\left\{\mu_{i j} \cdot \mu_{j}, v_{i j}+v_{j}-v_{i j} \cdot v_{j}\right\}
$$

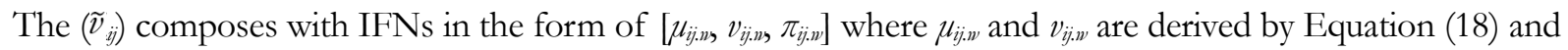

$$
\pi_{i j, W}=1-v_{i j}-v_{j}-\mu_{i j} \cdot \mu_{j}+v_{i j} \cdot v_{j}
$$

\begin{tabular}{|c|c|c|c|c|}
\hline \multirow{2}{*}{ Criteria } & \multicolumn{4}{|c|}{ Alternative } \\
\hline & A1 & A2 & A3 & A4 \\
\hline $\mathrm{C} 1$ & $(0.567,0.366,0.067)$ & $(0.620,0.308,0.072)$ & $(0.567,0.366,0.067)$ & $(0.620,0.308,0.072)$ \\
\hline $\mathrm{C} 2$ & $(0.540,0.335,0.125)$ & $(0.275,0.619,0.106)$ & $(0.352,0.536,0.111)$ & $(0.432,0.448,0.120)$ \\
\hline $\mathrm{C} 3$ & $(0.579,0.313,0.108)$ & $(0.545,0.346,0.109)$ & $(0.583,0.346,0.071)$ & $(0.638,0.286,0.076)$ \\
\hline $\mathrm{C} 4$ & $(0.343,0.524,0.133)$ & $(0.292,0.583,0.125)$ & $(0.207,0.696,0.097)$ & $(0.392,0.469,0.139)$ \\
\hline $\mathrm{C} 5$ & $(0.381,0.476,0.142)$ & $(0.363,0.502,0.135)$ & $(0.399,0.460,0.141)$ & $(0.434,0.419,0.146)$ \\
\hline C6 & $(0.415,0.469,0.116)$ & $(0.454,0.426,0.120)$ & $(0.454,0.426,0.120)$ & $(0.429,0.450,0.121)$ \\
\hline $\mathrm{C} 7$ & $(0.429,0.426,0.145)$ & $(0.319,0.554,0.127)$ & $(0.319,0.554,0.127)$ & $(0.405,0.450,0.144)$ \\
\hline $\mathrm{C} 8$ & $(0.392,0.469,0.139)$ & $(0.369,0.494,0.137)$ & $(0.369,0.494,0.137)$ & $(0.343,0.524,0.133)$ \\
\hline C9 & $(0.429,0.426,0.145)$ & $(0.332,0.531,0.137)$ & $(0.319,0.550,0.131)$ & $(0.404,0.453,0.143)$ \\
\hline C10 & $(0.461,0.390,0.148)$ & $(0.461,0.390,0.148)$ & $(0.429,0.426,0.145)$ & $(0.429,0.426,0.145)$ \\
\hline
\end{tabular}

Table 18. Aggregated weighted intuitionistic fuzzy decision

Step 3. Determine the positive ideal solution FPIS $\left(A^{+}\right)$and negative ideal solution NIS $\left(A^{-}\right)$.

The fuzzy positive ideal solutions FPIS $\left(A^{+}\right)$and fuzzy negative ideal solution FNIS $\left(A^{-}\right)$are determined by (Gerogiannis et al., 2011):

$$
A^{*}=\left(\mu_{A^{*} W}, v_{A^{*} W}\right) \text { and } A^{-}=\left(\mu_{A^{-} W}, v_{A^{-} W}\right)
$$

where

$$
\begin{aligned}
& \mu_{A^{*} W}=\left(\left(\max _{i} \mu_{i j, W} \mid j \in B\right),\left(\min _{i} \mu_{i j, W} \mid j \in C\right)\right) \\
& v_{A^{*} W}=\left(\left(\min _{i} v_{i j, W} \mid j \in B\right),\left(\max _{i} v_{i j, W} \mid j \in C\right)\right) \\
& \mu_{A^{-} W}=\left(\left(\min _{i} \mu_{i j, W} \mid j \in B\right),\left(\max _{i} \mu_{i j, W} \mid j \in C\right)\right) \\
& v_{A^{-} W}=\left(\left(\max _{i} v_{i j, W} \mid j \in B\right),\left(\min _{i} v_{i j, W} \mid j \in C\right)\right)
\end{aligned}
$$

Based on Table 18 and Equation 20, the IFPIS and IFNIS were determined as follows:

$A^{+}=[(0.620,0.308,0.072),(0.540,0.335,0.125),(0.638,0.286,0.076),(0.207,0.696,0.097),(0.434,0.419,0.146)$, (0.454,0.426,0.120), (0.429,0.426,0.145), (0.392,0.469,0.139), (0.429,0.426,0.145), (0.461,0.390,0.148)] 
$A^{-}=[(0.567,0.366,0.067),(0.275,0.619,0.106),(0.545,0.346,0.109),(0.392,0.469,0.139),(0.363,0.502,0.135)$, $(0.415,0.469,0.116),(0.319,0.554,0.127),(0.343,0.524,0.133),(0.319,0.550,0.131),(0.429,0.426,0.145)]$

Step 5. Calculate Euclidean distance of each alternative from FPIS and FNIS.

According to Szmidt and Kacprzy (2000), the distance of each alternative from FPIS $\left(S^{+}\right)$and FNIS $\left(S^{-}\right)$was calculated by using Equation (21) and Equation (22), respectively, and shown in Table 19.

$$
\begin{aligned}
& S^{+}=\sqrt{\frac{1}{2 n} \sum_{j=1}^{n}\left[\left(\mu_{i j, W}-\mu_{A^{*} W}\right)^{2}+\left(v_{i j, W}-v_{A^{*} W}\right)^{2}+\left(\pi_{i j, W}-\pi_{A^{*} W}\right)^{2}\right]} \\
& S^{-}=\sqrt{\frac{1}{2 n} \sum_{j=1}^{n}\left[\left(\mu_{i j, W}-\mu_{A^{-} W}\right)^{2}+\left(v_{i j, W}-v_{A^{-} W}\right)^{2}+\left(\pi_{i j, W}-\pi_{A^{-} W}\right)^{2}\right]}
\end{aligned}
$$

Step 6. Calculate the relative closeness coefficient $\left(C C_{i}\right)$ to the ideal solution.

The final score of each alternative was evaluated using closeness coefficient $C C_{i}$ which is defined in Equation (23) as below,

$$
C C_{i^{*}}=\frac{s_{i^{-}}}{s_{i^{*}+s_{i-}}}
$$

\begin{tabular}{|c|c|c|c|c|}
\hline & $\boldsymbol{S}^{+}$ & $s^{-}$ & Closeness Coefficient $\left(C C_{i}\right)$ & Ranking Order \\
\hline A1 & 0.013 & 0.024 & 0.641 & \multirow{4}{*}{$\mathrm{A} 1 \succ \mathrm{A} 4 \succ \mathrm{A} 3 \succ \mathrm{A} 2$} \\
\hline A2 & 0.025 & 0.010 & 0.280 & \\
\hline A3 & 0.019 & 0.017 & 0.461 & \\
\hline A4 & 0.018 & 0.017 & 0.498 & \\
\hline
\end{tabular}

Table 19. The distances toward FPIS $\left(S^{+}\right)$and FNIS $\left(S^{-}\right)$as well as Closeness Coefficient $\left(C C_{i}\right)$

\subsubsection{TOPSIS Method-based Connection Degree of Set Pair Analysis (SPA)}

TOPSIS method-based connection degree of Set Pair Analysis (SPA) was used to find optimal solution (Kumar \& Garg, 2017). The SPA provides a quantitative analysis to integrate the certainty and uncertainty by defining the connection number. Below is the procedure of solving Intuitionistic Fuzzy using connection number of Set Pair Analysis based on TOPSIS method. The connection number of the set pairs was evaluated following the procedure by Kumar and Garg (2017) as detailed below:

Step 1. Normalize the decision matrix.

Given the aggregated rating matrix in Table 17, the matrix was converted into the normalized decision matrix $\mathrm{R}=\left(r_{i j}\right)_{n \times n}$ where $r_{i j}=\tilde{u}_{i j}+\tilde{v}_{i j}$ which was obtained as follows

$$
r_{i j}=\left\{\begin{array}{c}
\alpha_{i j} ; \text { for benefit type criteria } \\
\alpha_{i j}^{c} ; \text { for cost type criteria }
\end{array}\right\}
$$

where $\alpha_{i j}^{c}=\left(\tilde{v}_{i j}, \widetilde{u}_{i j}\right)$ is the pair of IFN $\alpha_{i j}=\left(\widetilde{u}_{i j}, \widetilde{v}_{i j}\right)$. The normalized decision matrix is shown in Table 20. 


\begin{tabular}{|c|c|c|c|c|c|}
\hline & C1 & C2 & C3 & C4 & C5 \\
\hline A1 & $(0.706,0.238)$ & $(0.700,0.200)$ & $(0.700,0.200)$ & $(0.283,0.613)$ & $(0.579,0.313)$ \\
\hline A2 & $(0.772,0.618)$ & $(0.356,0.542)$ & $(0.659,0.238)$ & $(0.372,0.521)$ & $(0.551,0.346)$ \\
\hline A3 & $(0.706,0.238)$ & $(0.456,0.443)$ & $(0.706,0.238)$ & $(0.542,0.370)$ & $(0.605,0.291)$ \\
\hline A4 & $(0.772,0.168)$ & $(0.560,0.336)$ & $(0.772,0.168)$ & $(0.200,0.700)$ & $(0.659,0.238)$ \\
\hline$A^{+}$ & $(0.772,0.168)$ & $(0.700,0.200)$ & $(0.772,0.168)$ & $(0.542,0.370)$ & $(0.659,0.238)$ \\
\hline$A^{-}$ & $(0.706,0.238)$ & $(0.356,0.542)$ & $(0.659,0.238)$ & $(0.200,0.700)$ & $(0.551,0.346)$ \\
\hline & $\mathbf{C 6}$ & $\mathbf{C} 7$ & $\mathbf{C} 8$ & $(0.700,0.200)$ & $(0.659,0.238)$ \\
\hline A1 & $(0.560,0.336)$ & $(0.613,0.283)$ & $(0.700,0.200)$ & $(0.542,0.346)$ & $(0.659,0.238)$ \\
\hline A2 & $(0.613,0.283)$ & $(0.456,0.443)$ & $(0.659,0.238)$ & $(0.521,0.372)$ & $(0.613,0.283)$ \\
\hline A3 & $(0.613,0.283)$ & $(0.456,0.443)$ & $(0.659,0.238)$ & $(0.659,0.238)$ & $(0.613,0.283)$ \\
\hline A4 & $(0.579,0.313)$ & $(0.579,0.313)$ & $(0.613,0.283)$ & $(0.700,0.200)$ & $(0.659,0.238)$ \\
\hline$A^{+}$ & $(0.613,0.283)$ & $(0.613,0.283)$ & $(0.700,0.200)$ & $(0.521,0.372)$ & $(0.613,0.283)$ \\
\hline$A^{-}$ & $(0.560,0.336)$ & $(0.456,0.443)$ & $(0.613,0.283)$ & $\mathbf{C})$ \\
\hline
\end{tabular}

Table 20. Normalized decision matrix, PIS and NIS, in the form of IFNs

Aggregrated fuzzy weight in Table 16 was transformed to constant weight vector $\left(\omega_{j}\right)$ (by calculating closeness coefficient of each indicator following Equation (13) - Equation (15) as shown in Table 21. As the sum of weights should be equal to 1 , normalization is applied to closeness coefficient to determine the final constant weights.

\begin{tabular}{|c|l|l|l|l|l|l|l|l|r|r|}
\hline & C1 & C2 & C3 & C4 & C5 & C6 & C7 & C8 & C9 & C10 \\
\hline$d_{\nu}\left(A^{-}\right)$ & 0.260 & 0.290 & 0.226 & 0.564 & 0.428 & 0.333 & 0.374 & 0.564 & 0.491 & 0.374 \\
\hline$d_{\nu}\left(A^{+}\right)$ & 1.157 & 1.136 & 1.192 & 0.874 & 1.012 & 1.092 & 1.068 & 0.874 & 0.949 & 1.068 \\
\hline$C C$ & 0.816 & 0.797 & 0.841 & 0.608 & 0.703 & 0.767 & 0.741 & 0.608 & 0.659 & 0.741 \\
\hline Weight $\left(\omega_{j}\right)$ & 0.112 & 0.109 & 0.115 & 0.084 & 0.097 & 0.105 & 0.102 & 0.084 & 0.091 & 0.102 \\
\hline
\end{tabular}

Table 21. Weight of criteria

Step 2. Determine the PIS and NIS of the alternative.

Positive ideal solution (PIS) and negative ideal solution (NIS) were computed using Equation (25) as below,

$$
A^{+}=\left(u_{j}^{+}, v_{j}^{+}\right)=\left(\max _{i} u_{i j}, \min _{i} v_{i j}\right) \text { and } A^{-}=\left(u_{j}^{-}, v_{j}^{-}\right)=\left(\min _{i} u_{i j}, \max _{i} v_{i j}\right)
$$

The positive and negative ideal solutions are shown in Table 20.

Step 3. Determine the connection number of each alternative proximity to PIS and NIS.

The connection number of the set pairs $H\left(r_{i j}, A^{+}\right)$and $H\left(r_{i j}, A^{-}\right)$denoted by $\mu_{i j}^{+}$and $\mu_{i j}^{-}$respectively was defined by Kumar and Garg (2017) as follows:

$$
\mu_{i j}^{+}=a_{i j}^{+}+c_{i j}^{+} k \text { and } \mu_{i j}^{-}=a_{i j}^{-}+c_{i j}^{-} k
$$

Where $a_{i j}^{+}=\left(\frac{u_{i j}}{u_{j}^{+}} \times \frac{v_{j}^{+}}{v_{i j}}\right)$ and $a_{i j}^{-}=\left(\frac{u_{j}^{-}}{u_{i j}} \times \frac{v_{i j}}{v_{j}^{-}}\right)$are identify degrees with proximity to PIS and NIS respectively, whereas $c_{i j}^{+}=\left(\frac{u_{j}^{+}-u_{i j}}{u_{j}^{+}} \times \frac{v_{i j}-v_{j}^{+}}{v_{i j}}\right)$ and $c_{i j}^{-}=\left(\frac{u_{i j}-u_{j}^{-}}{u_{i j}} \times \frac{v_{j}^{-}-v_{i j}}{v_{j}^{-}}\right)$are contrary degrees which is remote from PIS and NIS respectively. 
The connection number for overall decision making to select the best alternative was defined as:

$$
\mu_{i j}=a_{i j}+c_{i j} z
$$

Where $a_{i j}=a_{i j}{ }^{+} \times c_{i j}^{-}$represents the overall identity degree between $A_{i}$ and PIS, and $c_{i j}=c_{i j}{ }^{+} \times a_{i j}{ }^{-}$represents the overall contrary degree between the alternative $A_{i}$ and NIS. Table 22 indicates the connection number of each alternative.

\begin{tabular}{|c|c|c|c|c|c|}
\hline & C1 & C2 & C3 & C4 & C5 \\
\hline A1 & $0.000+0.025 z$ & $0.310+0.000 z$ & $0.007+0.012 z$ & $0.012+0.117 z$ & $0.003+0.025 z$ \\
\hline A2 & $0.025+0.000 z$ & $0.000+0.310 z$ & $0.000+0.043 z$ & $0.058+0.036 z$ & $0.000+0.051 z$ \\
\hline A3 & $0.000+0.025 z$ & $0.012+0.122 z$ & $0.000+0.024 z$ & $0.297+0.000 z$ & $0.011+0.012 z$ \\
\hline A4 & $0.025+0.000 z$ & $0.066+0.032 z$ & $0.043+0.000 z$ & $0.000+0.297 z$ & $0.051+0.000 z$ \\
\hline & C6 & C7 & C8 & C9 & C10 \\
\hline A1 & $0.000+0.014 z$ & $0.092+0.000 z$ & $0.037+0.000 z$ & $0.118+0.000 z$ & $0.011+0.000 z$ \\
\hline A2 & $0.014+0.000 z$ & $0.000+0.092 z$ & $0.009+0.007 z$ & $0.001+0.086 z$ & $0.011+0.000 z$ \\
\hline A3 & $0.014+0.000 z$ & $0.000+0.092 z$ & $0.009+0.007 z$ & $0.000+0.118 z$ & $0.000+0.011 z$ \\
\hline A4 & $0.002+0.005 z$ & $0.053+0.003 z$ & $0.000+0.037 z$ & $0.060+0.005 z$ & $0.000+0.011 z$ \\
\hline
\end{tabular}

Table 22. Connection number of each alternative

Step 4. Determine the relative weighted connection number.

The weighted connection number of set pair under the set of criteria weights is defined as:

$$
\mu_{A_{i}}=a_{j}+c_{j} 2
$$

Where $a_{i}=\sum_{t=1}^{n} \omega_{j} a_{i j}$ is the overall identity degree between the alternative $A_{i}$ dan PIS, whereas $c_{i}=\sum_{t=1}^{n} \omega_{j} c_{i j}$ is the overall contrary degree between the alternative $A_{i}$ and NIS.

Step 5. Rank the alternative based on closeness coefficient and select the best one. The relative closeness degree of an alternative $\mathrm{A}$ is given as:

$$
T\left(\mu_{A_{i}}\right)=\frac{a_{i}}{a_{i}+c_{i}}
$$

\begin{tabular}{|c|c|c|c|}
\hline & $\begin{array}{l}\text { Weighted Connection } \\
\text { Number (CN) }\end{array}$ & $\begin{array}{l}\text { Closeness Coefficient } \\
\left(C C_{i}\right)\end{array}$ & Ranking Order \\
\hline A1 & $0.060+0.018 z$ & 0.771 & \multirow{4}{*}{$\mathrm{A} 1 \succ \mathrm{A} 4 \succ \mathrm{A} 3 \succ \mathrm{A} 2$} \\
\hline A2 & $0.011+0.065 z$ & 0.146 & \\
\hline A3 & $0.029+0.042 z$ & 0.412 & \\
\hline A4 & $0.031+0.034 z$ & 0.478 & \\
\hline
\end{tabular}

Table 23. Weighted connection number, closeness coefficient, and ranking order

\section{Discussion}

It is argued that effective planning decision should essentially take into account all participants with a variety of types and values. Based on previous experience, the location that seems to be feasible was found not practical, 
hence the UDC implementation has been unsuccessful. Therefore, considering multifaceted aspects in decision making including spatial aspect is of importance. Moreover, when it comes to location decision making, decision makers usually encounter uncertainty/vagueness due to complex inter-relationship among variables and unavailability of precise data to base decision making. The two-step proposed framework has contributed to the development of multi-criteria decision making which incorporates spatial aspect, uncertainty, and representative participants in UDC location for Yogyakarta province. The proposed framework has included government, practitioners, and logistic experts. The framework derives weights that used to transform geographical data to evaluate feasible alternatives to help identifying feasible and practical areas. Finally, the framework then considers uncertainty and complexity (e.g., multi-criteria, multiple stakeholders) in selecting UDC location by fuzzy multi-criteria decision making.

The first step has evaluated spatial feasibility of the potential UDC locations. It appears that the current UDC plan (Jogja Inland Port) is located outside the area of the city and so is the best location based on the evaluation of the proposed framework. Furthermore, the proposed framework has provided that the best UDC location is located in Berbah (Sleman district), which is consistent with the results of using Intuitionistic Fuzzy TOPSIS and SPA. There is no conflict in selecting A1 (Berbah, Sleman district) as the best alternative location for the prospective UDC. Statistically, there is no significant difference with respect to closeness coefficient of alternatives between those of the proposed framework and those of using Intuitionistic Fuzzy TOPSIS $\left(C h i^{2}=0.173, d f=3, p=0.982\right)$ and Intuitionistic Fuzzy SPA $\left(C h i^{2}=0.408, d f=3, p=0.939\right)$. Furthermore, the selected best UDC location seems to be robust when the accessibility, costs, and proximity to customers are not issues.

Given the consistent result of the best alternative, the proposed framework is promising to be implemented in evaluating UDC Location. The proposed framework provides balance between practicality and utility. The proposed framework is simple enough to be used in comparison to other more complex decision-making approaches, whereas still able to provide similar results to those of the sophisticated approaches. However, the limitation of the proposed approach is corresponding to the shortcoming of TOPSIS in which Euclidean distance neglects the correlation of attributes so that it may not fit to the case where high correlation attributes exist. Moreover, Fuzzy TOPSIS resulting in slight differences on closeness coefficients among alternatives may create difficulty in making decision. On the other hand, Intuitionistic Fuzzy TOPSIS and SPA provides substantial differences among alternatives.

\section{Conclusion}

Location planning for the UDC is a daunting task as it involves many stakeholders to be involved, many factors to be considered, uncertainty in decision parameters, and vagueness of decision-making. The present study complements the previous feasibility study of the similar context in a way that the present study focuses on involving multi-criteria, multiple stakeholders, spatial aspect, and uncertainty in decision-making whereas the previous study have been set in a certain environment. The present study proposes a framework to evaluate and select the appropriate location for Urban Distribution Center (UDC) in Yogyakarta Special Region Province, Indonesia by combining spatial analysis and multi-criteria decision-making. The study contributes to a more comprehensive insight when it comes to practicality and feasibility toward UDC implementation. Ten criteria, i.e., accessibility, security, connectivity of multimodal transport, costs, environmental impact, proximity to customers, proximity to suppliers, resource availability, expansion possibility and service quality were considered. The proposed framework is applied to evaluate Jogja Inland Port, a potential UDC which has been prepared by the government since 2008. Results imply that Jogja Inland Port, appears to be not the best location among the other selected three locations. The best location for UDC lies in Berbah (Sleman district), east part of the city center. It is therefore necessary to extend the study to examine the best locations in real or near-real environmental setting, probably using a simulation tool, for the future research. As the study has involved the government, experts, and practitioners, future research could engage local residents to refine the results, as various stakeholders may have different preferences and goals. Government may focus on infrastructure-related issues, industrial practitioners may focus on economic and market-oriented issues, whereas residents may focus on safety, social and environmental aspects. In addition, from the methodological perspective, future research could apply interval-valued intuitionistic fuzzy based on Set Pair Analysis as proposed by Garg and Kumar (2018) or using other multi-criteria evaluation 
techniques such as ELECTRE (Benayoun, Roy \& Sussman, 1966), PROMETHEE (Brans \& Vincke, 1985), Analytic Network Process (Saaty, 1996) to evaluate consistency of the results. Another future research could compare results between ranking approach and optimization approach using multiple objective mathematical programming such as Sopha et al. (2016).

The theoretical contribution of present study lies in the proposed framework which is generic, thus can be applied in selecting any locations for different context, and the demonstration of the proposed framework to deal with UDC establishment in Yogyakarta Special Region Province which has not been previously explored. From a practical point of view, the present study provides empirical insights of the plausibility of the current UDC plan.

\section{Declaration of Conflicting Interests}

The authors declared no potential conflicts of interest with respect to the research, authorship, and/or publication of this article.

\section{Funding}

The authors gratefully acknowledge the supports from Indonesian Higher Education Directorate (DIKTI) through PSN (Penelitian Strategis Nasional) research grant and USAID through the SHERA program - Centre for Development of Sustainable Region (CDSR).

\section{References}

Agrebi, M., Abed, M., \& Omri, M.N. (2015). Urban distribution centers' location selection's problem: A survey. Proceeding of 4th IEEE International Conference on Advanced Logistics and Transport (ICALT). France. https://doi.org/10.1109/ICAdLT.2015.7136635

Allen, K., Browne, M., Woodburn, A., \& Leonardi, K. (2012). The role of urban consolidation centres in sustainable freight transport. Transport Reviews, 32, 473-490. https://doi.org/10.1080/01441647.2012.688074

Anand, N., Quak, H., van Duin, R., \& Tavasszy, L. (2012). City logistics modeling efforts: Trends and gaps - A review. Procedia - Social and Behavioral Sciences, 39, 101-115. https://doi.org/10.1016/j.sbspro.2012.03.094

Atanassov, K.T. (1986). Intuitionistic fuzzy sets. Fuzzy Sets and Systems, 20(1), 87-96. https://doi.org/10.1016/S01650114(86)80034-3

Awasthi, A., \& Chauhan, S.S. (2011). A hybrid integrating affinity diagram, AHP and fuzzy TOPSIS for sustainable city logistics planning. Mathematical and Computer Modelling, 36, 573-584.

Benayoun, R., Roy, B., \& Sussman, B. (1966). ELECTRE: une méthode pour guider le choix en présence de points de vue multiples. Note de Trav, 49.

Brans, J.P., \& Vincke, P. (1985). A preference ranking organization method: The PROMETHEE method for multiple criteria decision-making. Management Science, 31, 647-656. https://doi.org/10.1287/mnsc.31.6.647

Castro, D.M., \& Parreiras, F.S. (2018). A Review on Multi-Criteria Decision-Making for Energy Efficiency in Automotive Engineering. Applied Computing and Informatics. https://doi.org/10.1016/j.aci.2018.04.004

Chen, C.T., Lin, C.T., \& Huang, S.F. (2006). A fuzzy approach for supplier evaluation and selection in supply chain management. International Journal of Production Economics, 102, 289-301. https://doi.org/10.1016/j.ijpe.2005.03.009

Chen-Tung, C. (2001). A fuzzy approach to select the location of the distribution center. Fuz:y Sets and Systems, 11, 65-73. https://doi.org/10.1016/S0165-0114(98)00459-X

Chou, C., \& Chang, P. (2009). A fuzzy criteria decision making model for selecting the distribution center location in China: A Taiwanese Manufacturer's Perspective. Human Interface, 2, 140-148. https://doi.org/10.1007/978-3-64202559-4_16

Dernoncourt, F. (2013). Introduction to Fur:y Logic. Cambridge: Massachusetts Institute of Technology. 
Dhiman, R., Kalbar, P., \& Inamdar, A.B. (2018). GIS coupled multiple criteria decision making approach for classifying urban coastal areas in India. Habitat International, 71, 125-134.

https://doi.org/10.1016/j.habitatint.2017.12.002

Durbach, I.N., \& Stewart, T.K. (2012). Modelling uncertainty in multi-criteria decision analysis. European Journal of Operational Research, 223, 1-14. https://doi.org/10.1016/j.ejor.2012.04.038

Ertugrul, I., \& Karakasoglu, N. (2008). Comparison of fuzzy AHP and fuzzy TOPSIS methods for facility location selection. International Journal of Advance Manufacturing Technology, 39, 783-795. https://doi.org/10.1007/s00170-0071249-8

Garg, H., \& Kumar, K. (2018). Some aggregation operators for linguistic intuitionistic fuzzy set and its application to group decision-kaing process using the set pair analysis, Arabian Journal for Science and Engineering, 43, 3213-3227. https://doi.org/10.1007/s13369-017-2986-0

Gerogiannis, V.C., Fitsilis, P., \& Kameas, A.D. (2011). Using a Combined Intuitionistic Fuzzy Set-TOPSIS Method for Evaluating Project and Portfolio Management Information Systems. In: Iliadis, L., Maglogiannis, I., \& Papadopoulos, H. (Eds.), Artificial Intelligence Applications and Innovations. IFIP Advances in Information and Communication Technology (364). Springer, Berlin, Heidelberg. https://doi.org/10.1007/978-3-642-23960-1_9

Han, H., \& Trimi, S. (2018). A fuzzy TOPSIS method for performance evaluation of reverse logistics in social commerce platforms. Expert Systems with Applications, 103, 133-145. https://doi.org/10.1016/j.eswa.2018.03.003

Hatami-Marbini, A., \& Kangi, F. (2017). An extension of fuzzy TOPSIS for a group decision making with an application to Tehran stock exchange. Applied Soft Computing, 52(C), 1084-1097.

https://doi.org/10.1016/j.asoc.2016.09.021

Hu, Y., Wu, S., \& Cai, L. (2009). Fuzzy multi criteria decision making TOPSIS for Distribution center location selecting. Institute of Electrical and Electronics Engineers (IEEE), 2, 707-710.

Hwang, C.-L., \& Yoon, K. (1981). Multiple attribute decision making methods and ap-plications a State-of-the-Art survey. Berlin, Heidelberg: Springer-Verlag. https:/ / doi.org/10.1007/978-3-642-48318-9

Junior, F.R.L., Osiro, L., \& Carpinetti, L.C.R. (2014). A comparison between Fuzzy AHP and Fuzzy TOPSIS methods to supplier selection. Applied Soft Computing, 21, 194-209. https://doi.org/10.1016/j.asoc.2014.03.014

Kahraman, C., Pardalos, P.M., \& Du, D. (2008). Fuzay Multi-Criteria Decision Making: Theory and Applications with Recent Developments. Boston: Springer-Verlag. https://doi.org/10.1007/978-0-387-76813-7

Kazemi, H., \& Akinci, H. (2018). A land use suitability model for rainfed farming by Multi-criteria Decision-making Analysis (MCDA) and Geographic Information System (GIS). Ecological Engineering, 116, 1-6. https://doi.org/10.1016/j.ecoleng.2018.02.021

Kim, Y., Chung, E., Kun, S., \& Kim, S.U. (2013). Prioritizing the best sites for treated wastewater instream use in an urban watershed using fuzzy TOPSIS. Resources, Conservation, and Recycling, 73, 23-32.

https://doi.org/10.1016/j.resconrec.2012.12.009

Kumar, K., \& Garg, H. (2017). Connection number of set pair analysis based TOPSIS method on intuitionistic fuzzy sets and their application to decision making. Applied Intelligence. https://doi.org/10.1007/s10489-017-1067-0

Mishra, A.R. (2016). Intuitionistic Fuzzy information measures with application in rating of township development. Iranian Journal of furay systems, 13, 49-70.

Saaty, T.L. (1980). The Analytical Hierarchy Process, Planning, Priority Setting, Resource Allocation. New York: McGraw-Hill.

Saaty, T.L. (1996). Decision Making with Dependence and Feedback: The Analytic Network Process. Pittsburgh: RWS publications.

Seyedmohammadi, J., Samadian, F., Kafarzadeh, A.A., Ghorbanim, M.A., \& Shahbazi, F. (2018). Application of SAW, TOPSIS and fuzzy TOPSIS models in cultivation priority planning for maize, rapeseed and soybean crops. Geoderma, 310, 178-190. https://doi.org/10.1016/j.geoderma.2017.09.012 
Shao, Y., Chen, Q., \& Wei, Z. (2009). Logistics Distribution Center Location Evaluation Based on Genetic Algorithm and Fuzzy Neural Network. Communcations in Computer and Information Science, 51, 305-312. https://doi.org/10.1007/978-3-642-04962-0_35

Sopha, B.M., Asih, A.M.S., Pradana, F.D., Gunawan, H.E., \& Karuniawati, Y. (2016). Urban distribution center location. International Journal of Engineering Business Management, 8, 1-10. https://doi.org/10.1177/1847979016678371

Szmidt, E., \& Kacprzy, K.J. (2000). Distance between Intuitionistic Fuzzy Sets. Fuгzy Sets and Systems, 114, 505-518. https://doi.org/10.1016/S0165-0114(98)00244-9

Xu, Z.S. (2007). Intuitionistic Fuzzy Aggregation Operators. IEEE Transactions on Furzy Systems, 15, 1179-1187. https://doi.org/10.1109/TFUZZ.2006.890678

Zadeh, L.A. (1965). Fuzzy Sets. Information and Control, 8, 338-353. https://doi.org/10.1016/S0019-9958(65)90241-X

Journal of Industrial Engineering and Management, 2018 (www.jiem.org)

\section{(c) (1) (\$)}

Article's contents are provided on an Attribution-Non Commercial 4.0 Creative commons International License. Readers are allowed to copy, distribute and communicate article's contents, provided the author's and Journal of Industrial Engineering and Management's names are included. It must not be used for commercial purposes. To see the complete license contents, please visit https://creativecommons.org/licenses/by-nc/4.0/. 